\title{
Article
}

\section{Survey of Tsuruga Inhabitants Concerning Radiation and Its Risks}

\author{
Yoshihiko SHINODA ${ }^{1,3, *}$ and Naoki YAMANO ${ }^{2}$ \\ ${ }^{1}$ Department of Nuclear Power and Energy Safety Engineering, Graduate School of Engineering, University of Fukui, \\ 3-9-1 Bunkyo, Fukui-shi, Fukui 910-8507, Japan \\ ${ }^{2}$ Research Institute of Nuclear Engineering, University of Fukui, 1-2-4 Kanawa-cho, Tsuruga-shi, Fukui 914-0055, Japan \\ ${ }^{3}$ Japan Atomic Energy Agency, Tsuruga Head Office, 65-20 Kizaki, Tsuruga-shi, Fukui 914-8585, Japan
}

\begin{abstract}
The Fukushima Daiichi Nuclear Accident has led to changes in the acceptance of nuclear power in many people. The authors conducted an opinion survey of 300 adult inhabitants of Tsuruga city in Fukui Prefecture, Japan. The aim of this survey is to obtain people's opinions concerning radiation and its risks. Authors classified Tsuruga inhabitants on the basis of responses to questions on the concept and knowledge of risk and the cognition of radiation by factor and cluster analyses of multivariable analysis. Using the results of these analyses, Tsuruga inhabitants have been assigned to five categories: "acceptance group," "anxiety group," and three intermediate groups.
\end{abstract}

KEYWORDS: opinion survey, Tsuruga City, ionizing radiation, health effect, risk communication, low dose, co evolution

\section{Introduction}

The accident at the Fukushima Daiichi Nuclear Power Plants in the wake of the Great East Japan Earthquake (hereinafter called the "Fukushima Accident"), on March 11, 2011, released radioactive materials into the environment and, consequently, forced local residents to evacuate the area. The released radioactive materials had an impact not only on the local residents but also, more or less, on society as a whole and aroused nationwide interest and concern.

Since 2013, the authors have undertaken practical research activities in Tsuruga City, Fukui Prefecture, concerning the health risks of low-dose radiation through an association with and the cooperation of Tsuruga City residents ${ }^{1}$. This activity aims to model a new risk communication method and establish its implementation concerning the health effects of low-dose radiation, which has become a social issue after the Fukushima Accident. As a part of this study activity, we conducted an awareness survey (hereinafter called the "Survey") of residents in Tsuruga to understand their attitudes towards radiation and the notion of the "level of risk" (this refers to the meaning of the term "risk").

* Corresponding author, E-mail: shinoda.yoshihiko@plum.plala.or.jp

DOI : 10.15669 /fukushimainsights.Vol.4.357

(C) 2021 Atomic Energy Society of Japan. All rights reserved.

Originally published in Transactions of the Atomic Energy Society of Japan (ISSN 1347-2879), Vol. 14, No. 2, p.95-112

(2015) in Japanese. (Japanese version accepted: November 27, 2014) 


\section{Survey Overview}

\section{Purpose of the Survey}

The purpose of the survey is to ascertain the awareness of risks and the level of knowledge on radiation among residents of Tsuruga City, an area where nuclear power plants are located (hereinafter called the "Power Plant Located Area"), after the Fukushima Accident. In the survey, we first try to ascertain the level of knowledge and perception of radiation and low-dose exposure among residents as well as their awareness of the associated impacts (e.g. what images are brought to mind and how they think about them). Considering the current status where such impacts are observed daily, we think that we will be able to measure the level of awareness with high sensitivity by asking questions related to everyday life. Diet is an essential part of life, and, therefore, interest in food and radiation has increased after the Fukushima Accident. Therefore, we decided to study awareness of the health effects of low-dose radiation together with the degree of awareness of food contamination and the notion of risk. We think that by obtaining responses about these issues and exploring the relationship between them will allow us to obtain substantial information.

However, it should be noted that there are variations in the interpretation of the notion of risk and it is hard to say that the notion of risk is unambiguously recognized as a common concept. This study is intended to explore how far the subjects recognize the concept of risk and how they interpret the concept and to focus on the relationship between the their awareness towards the risk concept and the radiation.

\section{Overview of Relevant Awareness Surveys}

In order to develop survey questions, we examined awareness surveys previously performed in Japan as reference materials. Table 1 shows representative awareness surveys for which results and survey forms are open to the public.

In surveys on radiation and radioactivity ${ }^{2-4)}$ performed before the Fukushima Accident, the focus was placed on understanding people's knowledge and attitudes to radiation. In 2012, after the accident, awareness surveys were conducted with residents of Fukushima City as subjects. These included one to help promote reconstruction plans in Fukushima Prefecture, including radiation reduction measures ${ }^{6}$, and one to determine residents' awareness of decontamination implementation plans ${ }^{7}$. In these surveys, questions were given under the assumption that radiation exposure, depending on the level, could potentially influence the health of residents. Also, an awareness survey concerning the Fukushima Accident ${ }^{8,9)}$ included questions on radiation and radioactivity. Countless awareness surveys, performed before and after the Fukushima Accident ${ }^{10,11)}$ regarding nuclear power in general, included questions on radiation. Awareness surveys on food safety ${ }^{12-14)}$ performed after the Fukushima Accident focus on consumer consciousness of radiation and low-dose exposure. However, in many of these surveys, the questions were restricted and, therefore, the results are superficial. In previous studies ${ }^{15-27)}$, no questions were asked in relation to public awareness of the effects of exposure to low-dose radiation or the level of public knowledge on the notion of risk. Such questions are asked in this study for the first time.

\section{Survey Structure}

We analyzed previous study examples and designed and created a questionnaire and survey method. The structure of the survey is as follows. 
Table 1 Overview of relevant awareness surveys

\begin{tabular}{|c|c|c|c|c|c|}
\hline & Survey date & Surveyed area & Main surveyed items & Items related to radioactivity & Reference \\
\hline \multirow{13}{*}{$\begin{array}{l}\text { Radiation/ } \\
\text { Radioactivity }\end{array}$} & 1963 & Nationwide & Radiation/Radioactivity & Knowledge and interest & 2) \\
\hline & 2001 & Nationwide & Radiation/Radioactivity & Perception and knowledge & 3) \\
\hline & 2001 & $\begin{array}{l}\text { Service areas of the Kansai } \\
\text { Electric Power }\end{array}$ & Radiation/Radioactivity & $\begin{array}{l}\text { Risks, perception and } \\
\text { concerns }\end{array}$ & 4) \\
\hline & 2012 & $\begin{array}{l}\text { Service areas of the Kansai } \\
\text { Electric Power }\end{array}$ & Radiation/Radioactivity & $\begin{array}{l}\text { Knowledge, education and } \\
\text { perception }\end{array}$ & 5) \\
\hline & 2012 & $\begin{array}{l}\text { Fukushima City (including } \\
\text { those who evacuated the } \\
\text { city) }\end{array}$ & $\begin{array}{l}\text { The Fukushima Accident } \\
\text { and Radiation/Radioactivity }\end{array}$ & $\begin{array}{l}\text { Concerns and response actions } \\
\text { after the Fukushima Accident }\end{array}$ & 6) \\
\hline & 2013 & Fukushima Prefecture & $\begin{array}{l}\text { Decontamination } \\
\text { implementation plans }\end{array}$ & $\begin{array}{l}\text { Radiation exposure level and } \\
\text { effects on health }\end{array}$ & 7) \\
\hline & 2013 & $\begin{array}{l}\text { Tokyo metropolitan area, } \\
\text { Kansai region and power } \\
\text { plant located area }\end{array}$ & Earthquake and tsunami & $\begin{array}{l}\text { Response actions after the } \\
\text { Fukushima Accident and } \\
\text { knowledge }\end{array}$ & 8) \\
\hline & 2011 & Nationwide & $\begin{array}{l}\text { Living conditions after } \\
\text { disaster }\end{array}$ & fears, and concerns & 9) \\
\hline & $2007-2013$ & Nationwide & $\begin{array}{l}\text { Nuclear power generation } \\
\text { (hereinafter called "nuclear } \\
\text { power") }\end{array}$ & $\begin{array}{l}\text { Necessity of nuclear power } \\
\text { use, perception }\end{array}$ & 10) \\
\hline & $2007-2014$ & Tokyo metropolitan area & Nuclear power and energy & $\begin{array}{l}\text { Concerns about and awareness } \\
\text { of environmental pollution }\end{array}$ & 11) \\
\hline & 2011 & Nationwide & Food safety & Impacts and knowledge & 12) \\
\hline & 2013-2014 & Nationwide & Food purchasing & Knowledge and impacts & 13) \\
\hline & 2011 & $\begin{array}{l}\text { Tokyo metropolitan area } \\
\text { and Kansai region }\end{array}$ & Food safety & $\begin{array}{l}\text { Concerns about radiation } \\
\text { exposure }\end{array}$ & 14) \\
\hline \multirow{14}{*}{$\begin{array}{l}\text { Including } \\
\text { power plant } \\
\text { located } \\
\text { area and } \\
\text { neighboring } \\
\text { areas }\end{array}$} & 1979 & Tsuruga City & $\begin{array}{l}\text { Knowledge and information } \\
\text { on nuclear power and } \\
\text { contribution to communities }\end{array}$ & No direct questions & $15,16)$ \\
\hline & 1980 & $\begin{array}{l}\text { Kasiwazaki City, Niigata } \\
\text { Prefecture }\end{array}$ & $\begin{array}{l}\text { Knowledge on nuclear } \\
\text { power, information and } \\
\text { contribution to communities }\end{array}$ & No direct questions & 17) \\
\hline & 1981 & $\begin{array}{l}\text { Hamaoka-cho, Shizuoka } \\
\text { Prefecture (at that time) }\end{array}$ & $\begin{array}{l}\text { Knowledge on nuclear } \\
\text { power, information and } \\
\text { contribution to communities }\end{array}$ & No direct questions & 18) \\
\hline & 1998 & $\begin{array}{l}\text { Kasiwazaki City and } \\
\text { Futaba-gun, Fukushima } \\
\text { Prefecture }\end{array}$ & $\begin{array}{l}\text { Risk awareness and nuclear } \\
\text { power }\end{array}$ & $\begin{array}{l}\text { Radioactive contamination } \\
\text { (comparison of hazardous } \\
\text { events) }\end{array}$ & 19) \\
\hline & 2000 & $\begin{array}{l}\text { Kasiwazaki-city and } \\
\text { Futaba-gun }\end{array}$ & $\begin{array}{l}\text { Community development } \\
\text { and energy policy }\end{array}$ & No direct questions & 20) \\
\hline & 2001 & $\begin{array}{l}\text { Iwaki City, Fukushima } \\
\text { Prefecture, etc. }\end{array}$ & $\begin{array}{l}\text { Community development } \\
\text { and energy policy }\end{array}$ & No direct questions & 20) \\
\hline & 2005 & $\begin{array}{l}\text { Kasiwazaki City, Niigata } \\
\text { City, etc. }\end{array}$ & $\begin{array}{l}\text { Economic advantages and } \\
\text { reasons for avoidance }\end{array}$ & $\begin{array}{l}\text { Concerns about radiation } \\
\text { exposure }\end{array}$ & 21) \\
\hline & 2006 & Fukui Prefecture & $\begin{array}{l}\text { Nuclear power, risk } \\
\text { awareness, and policy }\end{array}$ & No direct questions & 22) \\
\hline & 2007 & Ibaraki Prefecture & $\begin{array}{l}\text { Nuclear power, risk } \\
\text { awareness, and policy }\end{array}$ & No direct questions & 23) \\
\hline & 2008 & $\begin{array}{l}\text { Neighboring villages/ } \\
\text { town in Tsuruga City and } \\
\text { Mihama City }\end{array}$ & $\begin{array}{l}\text { Benefits and changes in } \\
\text { living environment }\end{array}$ & No direct questions & 24) \\
\hline & 2010 & $\begin{array}{l}\text { Tokai Village, Ibaraki } \\
\text { Prefecture and neighboring } \\
\text { municipalities }\end{array}$ & $\begin{array}{l}\text { Nuclear power, information } \\
\text { and regional community }\end{array}$ & No direct questions & 25) \\
\hline & 2011 & $\begin{array}{l}\text { Tokai Village, Ibaraki } \\
\text { Prefecture and neighboring } \\
\text { municipalities }\end{array}$ & $\begin{array}{l}\text { Nuclear power, information } \\
\text { and regional community }\end{array}$ & $\begin{array}{l}\text { Impression of explanation of } \\
\text { radiation }\end{array}$ & 25) \\
\hline & 2011 & $\begin{array}{l}\text { Mito City, Ibaraki } \\
\text { Prefecture }\end{array}$ & $\begin{array}{l}\text { Nuclear power, information } \\
\text { and regional community }\end{array}$ & $\begin{array}{l}\text { Impression of explanation of } \\
\text { radiation }\end{array}$ & 26) \\
\hline & 2012 & $\begin{array}{l}\text { Matsue City, Shimane } \\
\text { Prefecture }\end{array}$ & $\begin{array}{l}\text { Reopening of Shimane } \\
\text { Nuclear Power Plant }\end{array}$ & No direct questions & 27) \\
\hline
\end{tabular}


Respondents: $\quad$ Male and female residents 18 years and older, who live in Tsuruga City.

Number of respondents: 300 (sample size).

Sampling method: Quota sampling (sample 20 locations with a given probability in proportion to the population of Tsuruga City, and acquire responses from 300 respondents [20 locations $\times 15$ respondents] by allocating 15 respondents in proportion to the gender and age of the parent population of each location).

Survey method: $\quad$ Direct-visit and self-completion method.

Survey period: $\quad$ September 5-19, 2013.

Question items: $\quad$ (1) General matters;

(2) Awareness of radiation and radioactivity;

(3) Awareness of risks and food safety; and

(4) Awareness of effects of low-dose exposure.

In the survey, we avoided questions that directly asked about respondents' awareness of nuclear power generation. This was to distinguish our survey from a survey developed to determine whether respondents were for or against nuclear power. On this basis, we created a questionnaire consisting of only relevant question items. For question items (2), (3) and (4), we used a question style (hereinafter called the "5-point scale") where we provided opinions and statements and asked respondents what they thought about them (or whether they applied to them), giving five answer options: "I agree (It applies to me)," "I somewhat agree (It somewhat applies to me)," "Neither," "I somewhat disagree (It somewhat doesn't apply to me)," and "I disagree (It doesn't apply to me)." The questions used in this paper are listed in the Questionnaire (excerpted) in the Appendix. In this paper, questions are abbreviated as follows: "Q5-1." Questions 5, 6, 7 and 8 ask about residents' (a) awareness of radiation and radioactivity; (b) awareness of risks and food safety; (c) knowledge, experiences and attitude towards risks; and (d) awareness of low-dose exposure, respectively.

Also, in the figures and tables included in this study, answer options from "I agree (It applies to me)" to "I disagree (It doesn't apply to me)" are defined as "Positive," "Weak positive," "Neutral," "Weak negative," and "Negative" responses, respectively. Then, we scored the options at 1-point intervals, $-2,-1,0,1,2$, in the order from positive to negative answers, and analyzed (negative values indicate positive direction (answer) and positive values indicate negative direction (answer)).

\section{Survey Results}

\section{Survey Results}

\section{(1) Respondents' attributes}

Table 2 shows the gender and age demographics of the respondents. Regarding awareness surveys conducted in Power Plant Located Areas, we need to know in advance any connections between the respondents and the nuclear power industry. In this survey we asked the question, "Do you have any relatives living with you who are engaged in the nuclear power industry or radiation-related industries?" Several options for answers were provided, including "self" and "father/mother," allowing for multiple answers. Table 3 shows the results. It reveals that $44.0 \%$, nearly half, of respondents have relatives engaged in the nuclear power industry or radiation-related industries. To this same question, 7.7\% answered "self" and 20.3\%, the highest percentage, 
Table 2 Gender and age of respondents

\begin{tabular}{cccc}
\hline Age & Male & Female & Total \\
\hline $18-29$ & $8.0 \%$ & $7.3 \%$ & $15.3 \%$ \\
$30-39$ & $8.7 \%$ & $8.0 \%$ & $16.7 \%$ \\
$40-49$ & $8.0 \%$ & $7.3 \%$ & $15.3 \%$ \\
$50-59$ & $8.3 \%$ & $7.7 \%$ & $16.0 \%$ \\
$60-69$ & $8.3 \%$ & $8.3 \%$ & $16.6 \%$ \\
70 and over & $8.0 \%$ & $12.0 \%$ & $20.0 \%$ \\
\hline Total & $49.3 \%$ & $50.7 \%$ & $100.0 \%$ \\
\hline
\end{tabular}

Table 3 Respondents' relationships with those engaged in the nuclear power industry and radiation-related industries

\begin{tabular}{cc}
\hline \multicolumn{3}{c}{ Nuclear/radiation industry workers } \\
\hline No & $56.0 \%$ \\
\hline Yes & $44.0 \%$ \\
\hline Response rate for each option (multiple selection is allowed) \\
\hline Self & $7.7 \%$ \\
Father/Mother & $5.3 \%$ \\
Grandson/Granddaughter & $3.3 \%$ \\
Relative & $7.7 \%$ \\
Spouse & $1.3 \%$ \\
Children & $4.0 \%$ \\
Brother/Sister & $20.3 \%$ \\
Other & $4.0 \%$ \\
\hline Respondent rate for those who chose "self" (selection rate of "self") \\
1 & $36.0 \%(13.8 \%)$ \\
2 & $6.7 \%(20 \%)$ \\
3 & $1.0 \%(100 \%)$ \\
4 & $0.3 \%(100 \%)$ \\
\hline
\end{tabular}

answered "brother/sister." The maximum number of answers selected was four. Thirty-Six percent (36\%) of respondents only selected one answer; of that $36 \%, 13.8 \%$ chose "self."

It should be noted that the scope of the definition of "those engaged in the nuclear power industry and radiation-related industries" was interpreted by each respondent. Also, when we refer to the relationships with the people so engaged as "personal relationships" that may have impact on the awareness of respondents, we must interpret it as only a partial capturing of personal relationships of Tsuruga City residents because the personal relationships of each individual may also influence the respondents' judgment.

\section{(2) Questions concerning radiation and radioactivity}

In the Questionnaire listed in the Appendix (Q5), there are 15 questions concerning radiation and radioactivity and respondents were asked to register their level of agreement with each question using options on a 5-point scale. The Questionnaire included questions concerning respondents' purchasing behavior and adequacy of purchasing restrictions in light of their views towards radiation (such as whether radiation is evil or dangerous) and respondents' knowledge and concerns about nuclear power. However, some questions, such as Q5-2, which states, "I cannot classify radiation and radioactivity as either good or bad," frames the issue both in terms of a respondent's viewpoint and knowledge of radiation and radioactivity.

Table 4 shows the responses to all questions. It should be noted that the total of some 
Table 4 Responses to the questions concerning radiation and radioactivity

\begin{tabular}{|c|c|c|c|c|c|c|c|c|}
\hline & & Positive & $\begin{array}{c}\text { Weak } \\
\text { positive }\end{array}$ & Neutral & $\begin{array}{c}\text { Weak } \\
\text { negative }\end{array}$ & Negative & Average & Variance \\
\hline Q5-1 & $\begin{array}{l}\text { I think radiation and radioactivity } \\
\text { are evil. }\end{array}$ & $12.7 \%$ & $15.3 \%$ & $36.3 \%$ & $13.3 \%$ & $21.3 \%$ & 0.15 & 1.63 \\
\hline Q5-2 & $\begin{array}{l}\text { I cannot classify radiation and } \\
\text { radioactivity as good or bad. }\end{array}$ & $25.3 \%$ & $19.7 \%$ & $32.0 \%$ & $8.0 \%$ & $13.3 \%$ & -0.36 & 1.70 \\
\hline Q5-3 & $\begin{array}{l}\text { I think radiation and radioactivity } \\
\text { are horrible. }\end{array}$ & $36.7 \%$ & $28.0 \%$ & $21.3 \%$ & $5.0 \%$ & $8.0 \%$ & -0.80 & 1.48 \\
\hline Q5-4 & $\begin{array}{l}\text { I think radiation and radioactivity } \\
\text { can sometimes be useful for human } \\
\text { beings. }\end{array}$ & $53.0 \%$ & $28.3 \%$ & $14.0 \%$ & $1.0 \%$ & $3.0 \%$ & -1.27 & 0.92 \\
\hline Q5-5 & $\begin{array}{l}\text { I think radiation and radioactivity } \\
\text { can be horrible or not horrible, } \\
\text { depending on the level of radiation. }\end{array}$ & $54.3 \%$ & $24.7 \%$ & $14.0 \%$ & $1.7 \%$ & $4.3 \%$ & -1.23 & 1.10 \\
\hline Q5-6 & $\begin{array}{l}\text { I think that radiation and } \\
\text { radioactivity are around us. }\end{array}$ & $76.7 \%$ & $17.0 \%$ & $5.0 \%$ & $0.0 \%$ & $0.7 \%$ & -1.69 & 0.41 \\
\hline Q5-7 & $\begin{array}{l}\text { I think the effects of internal } \\
\text { exposure are greater than the effects } \\
\text { of external exposure in Fukushima } \\
\text { Prefecture. }\end{array}$ & $23.0 \%$ & $24.3 \%$ & $41.3 \%$ & $5.0 \%$ & $5.7 \%$ & -0.54 & 1.15 \\
\hline Q5-8 & $\begin{array}{l}\text { I am concerned about the radiation } \\
\text { and radioactivity around us. }\end{array}$ & $16.0 \%$ & $18.3 \%$ & $25.7 \%$ & $14.7 \%$ & $25.0 \%$ & 0.14 & 1.96 \\
\hline Q5-9 & $\begin{array}{l}\text { I am concerned about radioactive } \\
\text { elements in tap water. }\end{array}$ & $11.7 \%$ & $14.0 \%$ & $26.7 \%$ & $17.0 \%$ & $30.3 \%$ & 0.40 & 1.83 \\
\hline Q5-10 & $\begin{array}{l}\text { I am concerned about radioactive } \\
\text { elements in milk and dairy products. }\end{array}$ & $10.0 \%$ & $17.0 \%$ & $27.3 \%$ & $16.3 \%$ & $29.3 \%$ & 0.38 & 1.77 \\
\hline Q5-11 & $\begin{array}{l}\text { I think the current government } \\
\text { regulations ensure food safety, } \\
\text { including food from Fukushima. }\end{array}$ & $19.3 \%$ & $26.7 \%$ & $27.7 \%$ & $13.0 \%$ & $12.0 \%$ & -0.28 & 1.57 \\
\hline Q5-12 & $\begin{array}{l}\text { I want to avoid purchasing milk } \\
\text { and dairy products from Ibaraki and } \\
\text { Tochigi. }\end{array}$ & $11.7 \%$ & $17.7 \%$ & $32.3 \%$ & $13.7 \%$ & $24.3 \%$ & 0.21 & 1.71 \\
\hline Q5-13 & $\begin{array}{l}\text { I am concerned about radioactive } \\
\text { elements in food (agricultural, } \\
\text { animal and fishery products). }\end{array}$ & $19.7 \%$ & $24.3 \%$ & $26.0 \%$ & $11.0 \%$ & $18.3 \%$ & -0.16 & 1.85 \\
\hline Q5-14 & $\begin{array}{l}\text { I want to avoid purchasing food } \\
\text { (agricultural, animal and fishery } \\
\text { products) from Fukushima. }\end{array}$ & $17.3 \%$ & $19.0 \%$ & $27.7 \%$ & $14.0 \%$ & $22.0 \%$ & 0.04 & 1.91 \\
\hline Q5-15 & $\begin{array}{l}\text { I think the current regulation values } \\
\text { for radioactive materials in foods are } \\
\text { adequate. }\end{array}$ & $16.3 \%$ & $19.7 \%$ & $43.0 \%$ & $9.7 \%$ & $11.0 \%$ & -0.21 & 1.35 \\
\hline
\end{tabular}

responses does not reach 100\% due to invalid answers and rounding errors. In Figure 1, we described the distribution of answers for Q5-1 "Radiation is evil," Q5-3 "Radiation is horrible," Q5-8 "I am concerned about radiation around us," and Q5-15 "Regulation values for radioactive materials in foods are adequate," as representative examples of Question 5. The average values calculated after allocating scores to answer options are $0.15,-0.80,0.14$, and -0.21 , respectively. Among all respondents, more respondents provided negative answers for "Radiation is evil" and positive answers for "Radiation is horrible." Although respondents show different attitudes towards concerns about radiation, the results lean slightly toward the negative side.

Many respondents showed agreement with the statements in Q5-4, -5 and -6, which concern general knowledge on radiation. As for the questions regarding respondents' perception and concerns, many of the results do not follow normal distribution; for example, in some questions, the response rate for a negative answer is higher than that for a weak negative answer. 


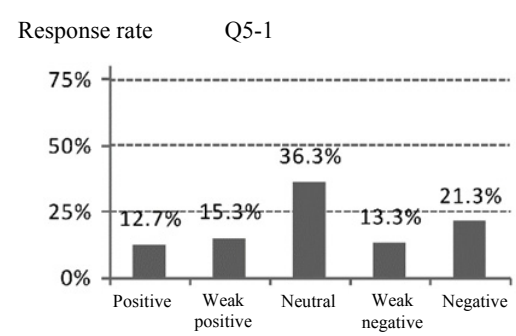

(1) Radiation is evil

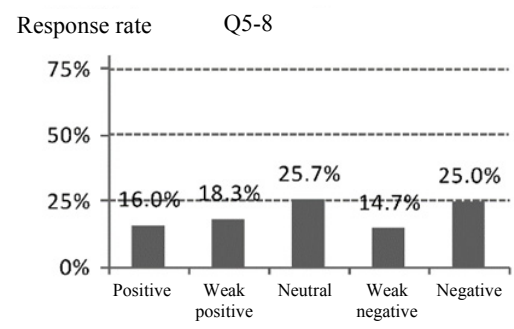

(3) I am concerned about radiation

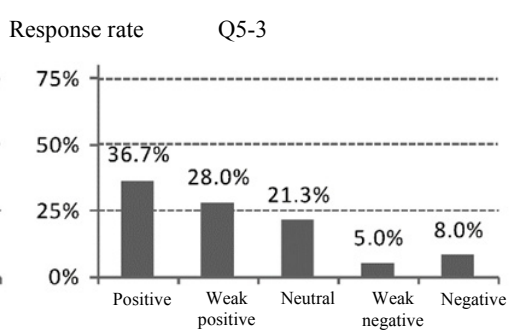

(2) Radiation is horrible

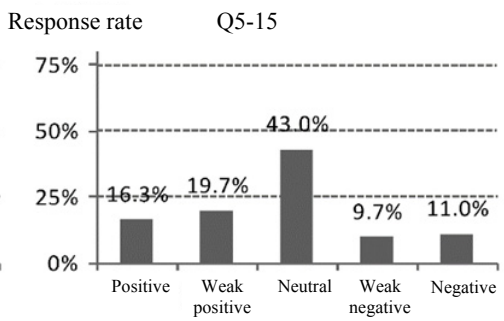

(4) Regulation values for radioactive materials in foods are adequate

"Answer options"

Positive: "I agree (It applies to me)."

5-Point Scale score

\begin{tabular}{lr}
\hline Weak positive: "I somewhat agree (It somewhat applies to me)." & -2 \\
\hline Neutral: "I neither agree nor disagree." & -1 \\
\hline Weak negative: “I somewhat disagree (It somewhat doesn't apply to me).” & 1 \\
\hline Negative: "I disagree (It doesn't apply to me)." & 2
\end{tabular}

Figure 1 Distribution of the response results of the questions concerning radiation and radioactivity (excerpted)

\section{(3) Questions concerning risks and food safety}

Q6 provides eleven questions on risks and food safety in Q6-1 to Q6-11. Q7 provides five questions on risks in Q7-1 to Q7-5.

Q6 presents typical opinions and asks respondents to register their level of agreement with them, providing multiple answer options from "I agree" to "I don't agree." Q7 measures respondents' knowledge, experience and attitudes, providing answer options from "It applies to me" to "It doesn't apply to me," and, therefore, Q7 is separate from Q6. Table $\mathbf{5}$ shows the responses to both Q6 and Q7. The results for Q6-8, concerning comparisons of the relative safety of tap water and mineral water, show that mineral water is considered safe. In Q6-11, concerning radiation materials in domestic food and imported food, more people answered that domestic food is safer. In these two questions, many respondents also had a neutral attitude and the response rates for negative answers were higher than those for weak negative answers. The results for Q7 regarding risks also showed a similar trend: the response rates for negative answers were higher than those for weak negative answers.

\section{(4) Questions concerning low-dose exposure}

Q8 provides thirteen questions on low-dose exposure, in Q8-1 to Q8-13, and asks respondents to register their level of agreement. Table 6 shows the responses. For Q8-1 "low-dose exposure is dangerous regardless of exposure dose" and Q8-13 "effects are passed on to offspring," opinions are divided. Although public trust in the government and experts is low, public trust in medical doctors is relatively high. Although we found, in Q8-9 and Q8-10, that 
Table 5 Responses to the questions concerning risks and food safety

\begin{tabular}{|c|c|c|c|c|c|c|c|c|}
\hline & & Positive & $\begin{array}{l}\text { Weak } \\
\text { Positive }\end{array}$ & Neutral & $\begin{array}{l}\text { Weak } \\
\text { Negative }\end{array}$ & Negative & Average & Variance \\
\hline Q6-1 & $\begin{array}{l}\text { I think chemical toxicity is more dangerous than } \\
\text { radioactive materials in food. }\end{array}$ & $28.0 \%$ & $25.7 \%$ & $42.3 \%$ & $1.3 \%$ & $2.3 \%$ & -0.76 & 0.91 \\
\hline Q6-2 & $\begin{array}{l}\text { We can trust the Food Safety Commission } \\
\text { regarding food safety. }\end{array}$ & $11.7 \%$ & $28.3 \%$ & $42.7 \%$ & $8.3 \%$ & $8.7 \%$ & -0.26 & 1.12 \\
\hline Q6-3 & $\begin{array}{l}\text { We can trust the Ministry of Health, Labour and } \\
\text { Welfare and Ministry of Agriculture, Forestry } \\
\text { and Fisheries of Japan regarding food safety. }\end{array}$ & $9.3 \%$ & $25.0 \%$ & $43.3 \%$ & $12.7 \%$ & $9.0 \%$ & -0.13 & 1.10 \\
\hline Q6-4 & I think there are various risks in our society & $55.3 \%$ & $32.0 \%$ & $10.3 \%$ & $0.7 \%$ & $1.0 \%$ & -1.40 & 0.62 \\
\hline Q6-5 & $\begin{array}{l}\text { I think radiation and radioactivity are just one } \\
\text { of many risks. }\end{array}$ & $43.7 \%$ & $32.7 \%$ & $16.7 \%$ & $2.7 \%$ & $4.0 \%$ & -1.09 & 1.07 \\
\hline Q6-6 & $\begin{array}{l}\text { I think some risks can have a bad influence on } \\
\text { us. }\end{array}$ & $38.0 \%$ & $32.0 \%$ & $26.0 \%$ & $2.0 \%$ & $1.3 \%$ & -1.03 & 0.85 \\
\hline Q6-7 & $\begin{array}{l}\text { I think some risks can have a good influence } \\
\text { on us. }\end{array}$ & $14.0 \%$ & $19.0 \%$ & $47.7 \%$ & $9.3 \%$ & $9.3 \%$ & -0.19 & 1.18 \\
\hline Q6-8 & I think mineral water is safer than tap water. & $15.7 \%$ & $21.3 \%$ & $43.3 \%$ & $6.0 \%$ & $13.3 \%$ & -0.20 & 1.40 \\
\hline Q6-9 & $\begin{array}{l}\text { I think the government and prefectures (local } \\
\text { government) should define criteria that clearly } \\
\text { determine what are risks. }\end{array}$ & $48.3 \%$ & $29.3 \%$ & $18.7 \%$ & $1.7 \%$ & $1.3 \%$ & -1.22 & 0.82 \\
\hline Q6-10 & $\begin{array}{l}\text { I think experts should define criteria that clearly } \\
\text { determine what are risks. }\end{array}$ & $48.3 \%$ & $28.3 \%$ & $20.0 \%$ & $1.3 \%$ & $2.0 \%$ & -1.20 & 0.88 \\
\hline Q6-11 & $\begin{array}{l}\text { I think domestic food contains less radioactive } \\
\text { materials than imported food. }\end{array}$ & $3.0 \%$ & $4.7 \%$ & $49.7 \%$ & $15.3 \%$ & $27.3 \%$ & 0.59 & 1.06 \\
\hline Q7-1 & I have thought about risks before. & $17.7 \%$ & $30.0 \%$ & $30.3 \%$ & $10.3 \%$ & $11.0 \%$ & -0.33 & 1.45 \\
\hline Q7-2 & I have been educated about risks. & $6.0 \%$ & $11.3 \%$ & $27.0 \%$ & $18.0 \%$ & $36.3 \%$ & 0.67 & 1.54 \\
\hline Q7-3 & I know how to determine risks. & $3.3 \%$ & $8.7 \%$ & $39.7 \%$ & $16.0 \%$ & $31.3 \%$ & 0.63 & 1.24 \\
\hline Q7-4 & I know the meaning of risks. & $21.7 \%$ & $29.7 \%$ & $29.0 \%$ & $7.7 \%$ & $10.3 \%$ & -0.45 & 1.46 \\
\hline Q7-5 & I determine risks by myself. & $17.3 \%$ & $30.7 \%$ & $32.3 \%$ & $6.3 \%$ & $12.0 \%$ & -0.35 & 1.43 \\
\hline
\end{tabular}

people recognize the effects of radiation on infants and toddlers, $43.3 \%$ of the respondents chose "Neither," in Q8-11, about the impact on the respondents themselves, which means they tend to be less worried about the effects of radiation on themselves.

\section{Analysis of the Survey}

\section{(1) Aggregation of the response results}

We summarized the response rates through the questions described in the above Sections III-1(2), (3) and (4). Details of the statistical methods used in this study can be found on Aoki's Website ${ }^{28)}$. From the general questions concerning radiation and risks, we can assume that respondents largely understand the risks associated with radiation. To Q5-6 "There is radiation around us," $76.7 \%$ gave positive responses and $17 \%$ gave weak positive responses, while $0.7 \%$ gave negative responses. For Q6-4 "There are various risks," the positive response rate is high, at $55.3 \%$. 
Table 6 Responses to the questions concerning low-dose exposure

\begin{tabular}{|c|c|c|c|c|c|c|c|c|}
\hline & & Positive & $\begin{array}{l}\text { Weak } \\
\text { positive }\end{array}$ & Neutral & $\begin{array}{c}\text { Weak } \\
\text { negative }\end{array}$ & Negative & Average & Variance \\
\hline Q8-1 & $\begin{array}{l}\text { I think low-dose exposure is scary regardless of } \\
\text { exposure dose. }\end{array}$ & $23.7 \%$ & $30.7 \%$ & $20.3 \%$ & $12.7 \%$ & $11.7 \%$ & -0.42 & 1.68 \\
\hline Q8-2 & $\begin{array}{l}\text { I think the effects of low-dose exposure are } \\
\text { uncertain. }\end{array}$ & $20.3 \%$ & $34.7 \%$ & $34.0 \%$ & $5.3 \%$ & $3.3 \%$ & -0.63 & 0.95 \\
\hline Q8-3 & $\begin{array}{l}\text { I think different experts say different things about } \\
\text { the effects of low-dose exposure. }\end{array}$ & $19.7 \%$ & $30.7 \%$ & $39.7 \%$ & $5.7 \%$ & $3.0 \%$ & -0.58 & 0.93 \\
\hline Q8-4 & $\begin{array}{l}\text { We cannot trust what the government says about } \\
\text { the effects of low-dose exposure. }\end{array}$ & $19.0 \%$ & $23.3 \%$ & $41.7 \%$ & $9.3 \%$ & $5.3 \%$ & -0.41 & 1.13 \\
\hline Q8-5 & $\begin{array}{l}\text { We cannot trust what experts say about effects of } \\
\text { low-dose exposure. }\end{array}$ & $11.3 \%$ & $14.7 \%$ & $51.7 \%$ & $14.3 \%$ & $6.3 \%$ & -0.10 & 0.99 \\
\hline Q8-6 & $\begin{array}{l}\text { We cannot trust what medical doctors say about } \\
\text { effects of low-dose exposure. }\end{array}$ & $8.0 \%$ & $9.3 \%$ & $53.3 \%$ & $19.3 \%$ & $8.3 \%$ & 0.11 & 0.93 \\
\hline Q8-7 & $\begin{array}{l}\text { I think one of the effects of low-dose exposure is } \\
\text { the development of cancer in the future. }\end{array}$ & $13.3 \%$ & $25.0 \%$ & $42.0 \%$ & $9.3 \%$ & $9.3 \%$ & -0.24 & 1.20 \\
\hline Q8-8 & $\begin{array}{l}\text { I think the effects of low-dose exposure not only } \\
\text { leads to the development of cancer in the future, } \\
\text { but also influences overall health. }\end{array}$ & $20.3 \%$ & $29.7 \%$ & $32.0 \%$ & $8.7 \%$ & $8.3 \%$ & -0.45 & 1.33 \\
\hline Q8-9 & $\begin{array}{l}\text { I think low-dose exposure negatively affects } \\
\text { infants. }\end{array}$ & $32.3 \%$ & $34.0 \%$ & $25.0 \%$ & $5.7 \%$ & $2.0 \%$ & -0.89 & 0.98 \\
\hline Q8-10 & $\begin{array}{l}\text { I think low-dose exposure negatively affects } \\
\text { toddlers and children. }\end{array}$ & $31.3 \%$ & $35.3 \%$ & $24.7 \%$ & $5.3 \%$ & $2.3 \%$ & -0.88 & 0.98 \\
\hline Q8-11 & $\begin{array}{l}\text { I am not concerned about any effects of low-dose } \\
\text { exposure on myself. }\end{array}$ & $13.3 \%$ & $12.7 \%$ & $43.3 \%$ & $15.7 \%$ & $14.3 \%$ & 0.05 & 1.39 \\
\hline Q8-12 & $\begin{array}{l}\text { I think the effects of low-dose exposure are } \\
\text { transmitted to others like a virus. }\end{array}$ & $2.7 \%$ & $3.0 \%$ & $28.0 \%$ & $17.7 \%$ & $47.7 \%$ & 1.05 & 1.13 \\
\hline Q8-13 & $\begin{array}{l}\text { I think the effects of low-dose exposure are } \\
\text { passed on to offspring. }\end{array}$ & $15.3 \%$ & $16.0 \%$ & $35.3 \%$ & $14.7 \%$ & $18.0 \%$ & 0.04 & 1.64 \\
\hline
\end{tabular}

To the same question, weak positive responses comprised $32 \%$. The reason people choose weak positive responses is assumed to stem from respondents' meekness and slight doubt and hesitation. For example, for Q8-10, Q8-2, and Q8-9, concerning the effects of low-dose exposure, weak positive responses were higher for these questions than for all other questions, with response rates of $35.3 \%, 34.7 \%$, and $34 \%$, respectively. As for the effects of low-dose exposure, we can say that it reflects the respondents' feeling that they cannot determine the significance of the impact even if they are aware of its existence. As for Q6-5, Q6-6 and Q6-4, concerning the notion of risk, the weak positive responses, representing $32 \%$, are difficult to analyze, but we can interpret them to mean that respondents avoided clearly indicating their responses because it is hard to understand the precise meaning of this concept.

Also, for questions where "Neither" was likely to be chosen as the response, these are considered to be questions where respondents more clearly show their hesitation (difficult to make a determination). As for Q8-6 and Q8-5, positive responses to the questions "We cannot trust what medical doctors and radiation experts say about the effects of low-dose exposure," 
were higher for both questions, at 53.3\% and 51.7\%, respectively. According to the response trends for Q8-2 and Q8-3, "Effects of low-dose exposure are uncertain and experts say different things," it would appear that respondents were hesitant to make a response about the credibility of experts and the significance of what they say.

As for the score results, the absolute values of the average values, which show the strength of positive or negative answers, in Q6-9 and Q6-10 "The government (experts) should clearly define criteria to determine what are risks," are significant at -1.22 and -1.20 , except for questions that ask respondents about their general knowledge of radiation and risks. This indicates that people have a strong desire to have risk determination criteria defined. The values of Q8-9 and Q8-10 "Low-dose exposure negatively affects infants (toddlers)" and Q5-3 "Radiation and radioactivity are horrible," are significant at $-0.88,-0.88$, and -0.80 , respectively, and respondents gave positive responses.

Evaluating values using unbiased variances, which indicate variation among responses, the value for Q5-8 is the highest at 1.96, followed by those for Q5-14, Q5-13, Q5-9, Q5-10, and Q5-12, which are related to people's concerns. This indicates that, although the level of anxiety is low overall, the variation in awareness is significant. Also, unbiased variances are large for all the questions in Q7, concerning risks. On the other hand, in the questions asking about people's general knowledge, their unbiased variances are small and that of Q5-6 "Radiation and radioactivity are around us," was the smallest at 0.41 , which means this is common knowledge. The unbiased variances of Q6-9 and Q6-10 "The government (local government) and experts should clearly define criteria to determine what are risks," are the smallest for questions that ask about the respondents' awareness, which means opinions are not so markedly split with respect to these questions.

\section{(2) Cross analysis}

First, we would like to evaluate the differences in response between males and females. As an evaluation example, we provide the cross-tabulation results and residual analysis results for Q5-14, "I want to avoid purchasing food from Fukushima," in Table 7 (1) and (2). By using cross-tabulation, we can evaluate overall relevance (independence). In addition, residual analysis allows us to test the specificity based on the difference between the statistically independent response rate and actual response rate of each cross-tabulation section. The P-value of the cross-tabulation between the response result and response difference between males and females in Q5-14, "I want to avoid purchasing food from Fukushima," is 0.0417 with $95 \%$ probability, and relevance is observed.

This means that there is a gap between males and females in their attitude as to whether food from Fukushima should be avoided. In the table, it was marked with an asterisk (*) in the upper left column.

In Table 7 (1), $14.3 \%$ of males and $7.7 \%$ of females chose negative responses. Residual analysis showed that a high percentage of males, $99 \%$ (indicated by ++ ), chose negative responses, while a low percentage of females (indicated by --), chose negative responses. Although females are more likely than males to choose positive to neutral responses and males are slightly more likely than females to choose weak negative responses, these are not statistically significant. In this example, we tend to draw the conclusion that the strength of the relevance based on cross-tabulation is significantly low, but the residual analysis revealed that there was a strong gap between males and females for negative responses. Regarding residual analysis, the meanings of symbols are provided below the table. Hereinafter, the symbols will be used for residual analysis results.

Table 7 (3) shows characteristic results from a residual analysis perspective. For Q5-1, 
Table 7 Cross-tabulation results based on the difference between males and females (excerpted)

Q5-14 I want to avoid purchasing food from Fukushima.

\begin{tabular}{|c|c|c|c|c|c|}
\hline$*$ & Positive & Weak positive & Neutral & Weak negative & Negative \\
\hline Males & $7.0 \%$ & $8.7 \%$ & $12.0 \%$ & $7.3 \%$ & $14.3 \%$ \\
\hline Females & $10.3 \%$ & $10.3 \%$ & $15.7 \%$ & $6.7 \%$ & $7.7 \%$ \\
\hline Total & $17.3 \%$ & $19.0 \%$ & $27.7 \%$ & $14.0 \%$ & $22.0 \%$ \\
\hline \multicolumn{6}{|c|}{ (1) Cross-tabulation table (Q5-14) } \\
\hline$*$ & Positive & Weak positive & Neutral & Weak negative & Negative \\
\hline Males & & & & & ++ \\
\hline Females & & & & & -- \\
\hline \multicolumn{6}{|c|}{$\begin{array}{l}\text { (2) Residual analysis results (Q5-14) } \\
\text { Q5-1 Radiation is evil. }\end{array}$} \\
\hline$* *$ & Positive & Weak positive & Neutral & Weak negative & Negative \\
\hline Males & & - & - & & ++ \\
\hline Females & & + & + & & -- \\
\hline \multicolumn{6}{|c|}{ Q5-3 Radiation is horrible. } \\
\hline & Positive & Weak positive & Neutral & Weak negative & Negative \\
\hline \multicolumn{6}{|l|}{ Males } \\
\hline Females & & & & & -9 \\
\hline \multicolumn{6}{|c|}{ Q8-1 Low-dose exposure is scary regardless of exposure level. } \\
\hline$* *$ & Positive & Weak positive & Neutral & Weak negative & Negative \\
\hline Males & -- & & & & ++ \\
\hline Females & ++ & & & & -- \\
\hline
\end{tabular}

(3) Characteristic of residual analysis results

\section{Upper left}

column

$* *(*)$ Relevant with $99 \%(95 \%)$ probability.

Response rate in the section is

\begin{tabular}{cl}
\hline++ & $\begin{array}{l}\text { high with } 99 \% \text { probability. } \\
\text { high with } 95 \% \text { probability. }\end{array}$ \\
\cline { 1 - 1 }+- & low with $99 \%$ probability. \\
low with $95 \%$ probability. \\
Blank: not significant but high. \\
Gray blank: not significant but low.
\end{tabular}

"Radiation is evil," the rate of negative responses was high in males and low in females. Overall, there was a difference between males and females, with $99 \%$ probability. Conversely, there was no significant difference between males and females in responses to Q5-3, "Radiation is horrible." For Q8-1 "Low-dose exposure is scary regardless of exposure level," the positive response rate was high in females and low in males, while the negative response rate was high in males and low in females. Generally, with respect to people's concerns about radiation and the impact on health of low-dose exposure, negative responses tend to be high in males and low in females. There was no significant difference between males and females regarding their knowledge of radiation itself.

Next, in Table 3, we divided and analyzed $56 \%$ of respondents who answered they had no relatives engaged in work related to nuclear power or radiation and the $44 \%$ of respondents who answered that either they, themselves, engaged in work related to nuclear power or radiation or that they had relatives who did. As indicated in Table 8 (1), a significant difference was observed for the same question as shown in Table 7 (3). However, for Q5-8 to Q8-15, regarding concerns about radiation, and Q8-7 to Q8-10, regarding future effects of low-dose exposure, there are no significant differences. This means that there is a difference in the level of anxiety 
Table 8 Results of residual analysis based on whether respondents have relatives who are engaged in radiation-related work or not (excerpted). Symbols in this table have the same meaning as those in Table 7

Q5-1 Radiation is evil.

\begin{tabular}{|c|c|c|c|c|c|}
\hline$*$ & Positive & Weak positive & Neutral & Weak negative & Negative \\
\hline No & ++ & & & & - \\
\hline Yes & -- & & & & + \\
\hline \multicolumn{6}{|c|}{ Q5-3 Radiation is horrible. } \\
\hline$* *$ & Positive & Weak positive & Neutral & Weak negative & Negative \\
\hline No & ++ & & - & & -- \\
\hline Yes & -- & & + & & ++ \\
\hline \multicolumn{6}{|c|}{ Q8-1 Low-dose exposure is scary regardless of exposure dose. } \\
\hline$* *$ & Positive & Weak positive & Neutral & Weak negative & Negative \\
\hline No & ++ & & & & - \\
\hline Yes & -- & & & & + \\
\hline \multicolumn{6}{|c|}{$\begin{array}{l}\text { (1) Residual analysis results of questions used in Table } 7 \text { (3) } \\
\text { Q6-2 We can trust the Food Safety Commission on food safety. }\end{array}$} \\
\hline$* *$ & Positive & Weak positive & Neutral & Weak negative & Negative \\
\hline No & & & -- & & \\
\hline Yes & & & ++ & & \\
\hline \multicolumn{6}{|c|}{$\begin{array}{l}\text { Q6-3 We can trust the Ministry of Health, Labour and Welfare and Ministry of Agriculture, Forestry and Fisheries of Japan } \\
\text { food safety. }\end{array}$} \\
\hline$* *$ & Positive & Weak positive & Neutral & Weak negative & Negative \\
\hline No & & ++ & -- & & \\
\hline Yes & & -- & ++ & & \\
\hline
\end{tabular}

(2) Characteristics of residual analysis results

between those who have relatives engaged in work related to the nuclear power and radiation industries and those who do not have relatives working in these industries. However, there is no difference in the level of anxiety regarding factors for which there is uncertainty.

Characteristic differences between these two groups are seen in the responses to Q6-2 and Q6-3, concerning trust in the Food Safety Commission, the Ministry of Health, Labour and Welfare, and Ministry of Agriculture, Forestry and Fisheries of Japan, respectively, on food safety. The results are presented in Table 8 (2). Respondents with relatives who are employed in the nuclear power and radiation industries are more likely to choose neutral answers than those without such relatives. We can see that those with relatives engaged in nuclear power and radiation work tend to hesitate from expressing their opinions where the grounds for making judgments are unclear and considering that the credibility of such organizations regarding food safety is unknown.

\section{(3) Analysis of questions on risks}

In the survey, although we capitalized risks as "RISKS" in six questions in Q6 and five questions in Q7, no annotation or description is provided for risks. By capitalizing "RISKS," we thought respondents would recognize risks and respond to questions based on their perception of them. Here, we tried to evaluate the level of respondents' knowledge on the notion of risk. In the responses to Q6-4 to Q6-7 and Q7-1 to Q7-5, the degree of positive and negative attitudes indicate the level of knowledge on the notion of risk. Even if risks are not clearly stated in other questions in Q7, some are semantic questions relevant to risks. However, we do not discuss these relationships here.

We analyze the relationships between the responses to questions where risks are clearly 
Table 9 Correlation analysis of questions on RISKS

\begin{tabular}{|c|c|c|c|c|c|c|c|c|c|c|c|}
\hline & Q6-4 & Q6-5 & Q6-6 & Q6-7 & Q6-9 & Q6-10 & Q7-1 & Q7-2 & Q7-3 & Q7-4 & Q7-5 \\
\hline & $\begin{array}{l}\text { I think there } \\
\text { are various } \\
\text { RISKS in } \\
\text { our society. }\end{array}$ & $\begin{array}{l}\text { I think } \\
\text { radiation and } \\
\text { radioactivity } \\
\text { are just one } \\
\text { of many } \\
\text { RISKS. }\end{array}$ & $\begin{array}{l}\text { I think } \\
\text { some } \\
\text { RISKS can } \\
\text { have a bad } \\
\text { influence } \\
\text { on us. }\end{array}$ & $\begin{array}{l}\text { I think } \\
\text { some } \\
\text { RISKS can } \\
\text { have a good } \\
\text { influence } \\
\text { on us. }\end{array}$ & $\begin{array}{l}\text { I think the } \\
\text { government } \\
\text { and } \\
\text { prefectures } \\
\text { (local } \\
\text { government) } \\
\text { should } \\
\text { clearly define } \\
\text { criteria to } \\
\text { determine } \\
\text { what are } \\
\text { RISKS. }\end{array}$ & $\begin{array}{l}\text { I think } \\
\text { experts } \\
\text { should } \\
\text { clearly } \\
\text { define } \\
\text { criteria to } \\
\text { determine } \\
\text { RISKS. }\end{array}$ & $\begin{array}{l}\text { I have } \\
\text { thought } \\
\text { about } \\
\text { RISKS } \\
\text { before. }\end{array}$ & $\begin{array}{l}\text { I have been } \\
\text { educated } \\
\text { about } \\
\text { RISKS. }\end{array}$ & $\begin{array}{l}\text { I know } \\
\text { how to } \\
\text { determine } \\
\text { RISKS. }\end{array}$ & $\begin{array}{l}\text { I know the } \\
\text { meaning of } \\
\text { RISKS. }\end{array}$ & $\begin{array}{l}\text { I determine } \\
\text { RISKS } \\
\text { myself. }\end{array}$ \\
\hline Q6-4 & & 0.32 & 0.24 & 0.05 & 0.05 & 0.04 & 0.10 & -0.04 & -0.04 & 0.10 & 0.08 \\
\hline Q6-5 & 0.45 & & 0.19 & -0.01 & -0.05 & 0.11 & 0.02 & 0.01 & -0.02 & -0.01 & 0.07 \\
\hline Q6-6 & 0.39 & 0.34 & & 0.09 & 0.04 & 0.05 & 0.04 & -0.12 & 0.08 & 0.02 & -0.05 \\
\hline Q6-7 & 0.04 & 0.02 & 0.09 & & -0.04 & -0.01 & -0.09 & 0.03 & -0.04 & -0.01 & 0.00 \\
\hline Q6-9 & 0.22 & 0.16 & 0.20 & -0.04 & & 0.73 & -0.04 & 0.02 & -0.07 & 0.10 & 0.00 \\
\hline Q6-10 & 0.24 & 0.22 & 0.22 & -0.03 & 0.75 & & 0.02 & -0.02 & 0.01 & -0.05 & 0.01 \\
\hline Q7-1 & 0.22 & 0.14 & 0.10 & -0.10 & 0.03 & 0.04 & & 0.10 & 0.10 & 0.22 & 0.09 \\
\hline Q7-2 & 0.02 & 0.01 & -0.07 & -0.04 & -0.04 & -0.06 & 0.36 & & 0.60 & 0.17 & -0.08 \\
\hline Q7-3 & 0.06 & 0.04 & 0.01 & -0.07 & -0.06 & -0.06 & 0.38 & 0.69 & & 0.09 & 0.14 \\
\hline Q7-4 & 0.26 & 0.15 & 0.10 & -0.06 & 0.13 & 0.08 & 0.47 & 0.42 & 0.45 & & 0.49 \\
\hline Q7-5 & 0.25 & 0.18 & 0.08 & -0.05 & 0.09 & 0.07 & 0.38 & 0.28 & 0.37 & 0.63 & \\
\hline
\end{tabular}

Upper triangular portion: Partial correlation coefficient, Lower triangular portion: correlation coefficient Outline characters indicate significant values (not zero) with $99 \%$ probability.

stated and other responses. In Table 9, the lower triangular portion across the diagonal line shows the correlation coefficient calculated based on scores allocated to each response. The upper triangular portion shows a partial correlation coefficient, eliminating the impact of questions other than the two questions being focused on. Outline numbers indicate significant values (not zero) with $99 \%$ probability. When a partial correlation coefficient is a large value, we can say that there is a direct relation (causality) between the two questions

Q6-4 to Q6-7 ask about respondents' knowledge on the notion of risk in general. The correlation coefficient and partial correlation coefficient between Q6-4 and Q6-5 become large, 0.45 and 0.32 , respectively. The partial correlation coefficient between Q6-4 and Q6-6 is 0.24 , which follows after that between Q6-4 and Q6-5. This means that those who think there are various risks in society also tend to consider radiation to be one of such risks. On the other hand, in Q6-7, "Some risks can have a good influence on us," no relationship is seen with other questions and it indicates that people do not consider risks as having an acceptable trade-off between harm and convenience.

The partial correlation coefficient between Q6-9 and Q6-10 is high at 0.73, which shows that when risk determination criteria are defined, people do not mind what entity (government, local government or experts) defines them. The partial correlation coefficients between Q6-4, Q6-5, and Q6-6 are all small. No relationship is seen between Q7-1 and Q7-5, which indicates that people's demand for having risk determination criteria defined is independent of their level of knowledge on the notion of risk.

Questions Q7-1 through Q7-5 are related to each other and their correlation coefficients are all significant. Partial correlation coefficients between Q7-2 and Q7-3 are large (0.60) suggesting that having been educated (or not educated) about risks and knowing (or not knowing) how to determine RISKS are directly related. Also, the relationship between Q7-4 and Q7-5, with a partial correlation coefficient of 0.49 , suggests that knowing the meaning of risks directly relates to people's attitude about determining risks for themselves. 
It is interesting that Q7-2, "I have been educated about RISKS," and Q7-5, "I determine what RISKS are myself," are not closely related (the correlation coefficient is 0.28 ). This suggests that there is a considerable number of respondents who determine risks by themselves even if they are not educated about them. The partial correlation coefficient is nearly zero, which suggests that there are factors other than education that influence people's attitudes about their ability to determine risks for themselves.

The relationship between Q7-3, "I know how to determine RISKS," and Q7-5, "I determine what RISKS are by myself," is relatively low. The responses in Table 5 suggest that many respondents answered that they determine risks for themselves even if they do not have a method for doing so. This may be because respondents think the risks that they determine for themselves and risks that they imagine are different. Also, we must note that the order of questions has some impact on responses throughout the survey.

Table 10 shows gender differences and differences between whether respondents have or do not have relatives who are engaged in nuclear/radiation-related industries, for questions between Q7-1 and Q7-5 concerning risks. In these questions, males tend to choose positive responses compared to females. However, in Q7-3 and Q7-5, which contain the word "determine", no difference is observed between the opinion of males and females. There are no significant differences between those with and those without relatives who are engaged in nuclear/ radiation-related-fields, for both positive and negative responses. For questions Q7-1, Q7-2, and Q7-3, many respondents with relatives who are engaged in nuclear/radiation-related fields chose neutral responses, which means that they have less confidence in their response.

\section{(4) Results of multivariate analysis}

In this paper, 44 questions are discussed. When we calculate correlation coefficients between

Table 10 Impact of respondents' attributes on questions concerning RISKS (residual analysis). Symbols in this table have the same meaning as those in Table 7

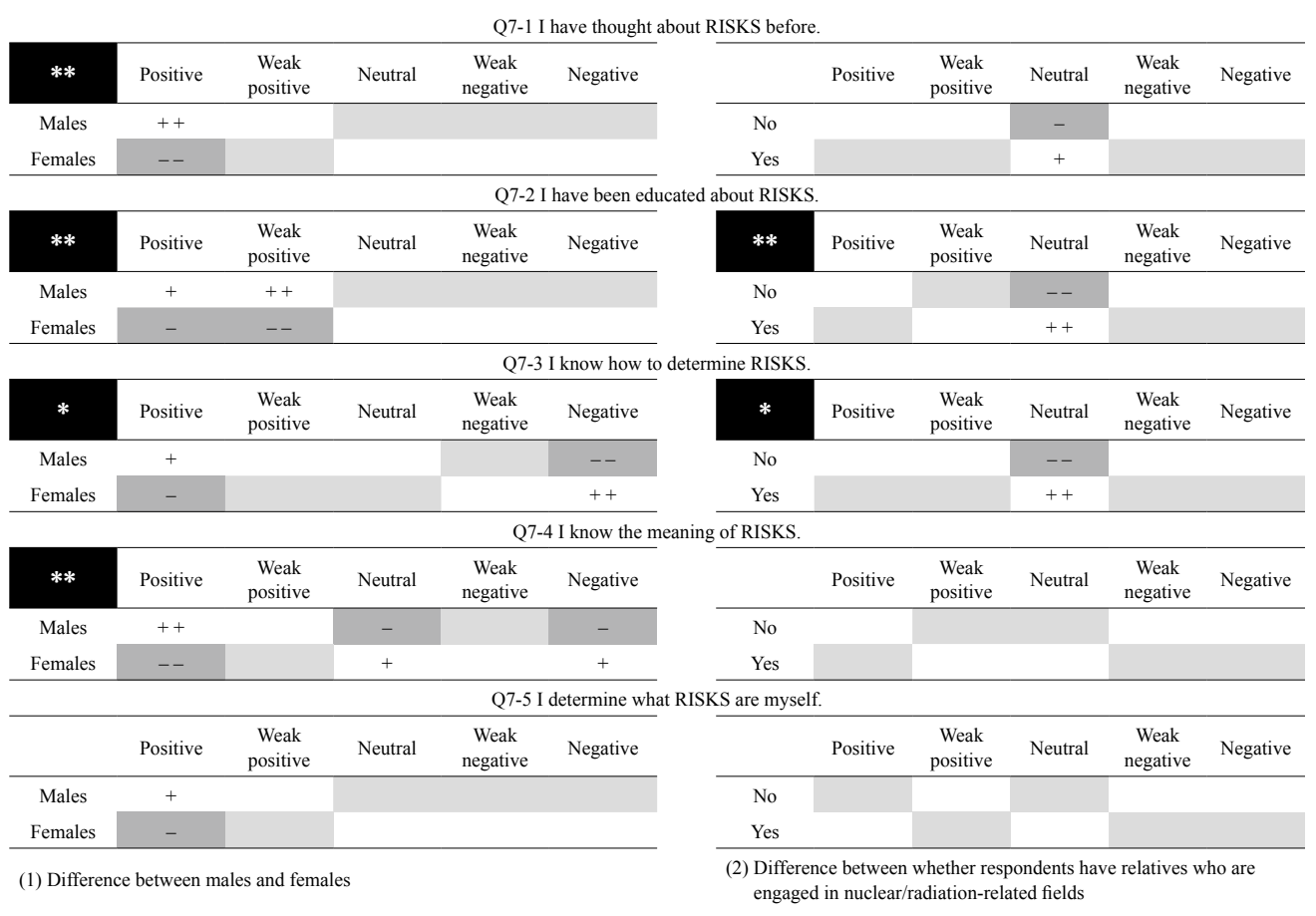


these responses, many of them are statistically significant and closely related. Response results have been analyzed individually, so far, but in this section they are analyzed using the multivariate analysis method, which uses multidimensional observed variables (*Observed variables refer to actually measured variables: Response data of the 44 questions).

(a) Adoption of factor analysis

First, we use factor analysis, which allows us to clarify latent structure. In this analysis, some observed variables may be discarded in the final analysis results because, in the course of analysis, observed variables with less commonality and those that simultaneously reflect multiple factors are eliminated and then the analysis is repeated. Also, as there are various methods used for the analysis, interpretation of results is sometimes difficult.

In this study, we used iterative principal factor analysis to extract factors considering the response distribution and Promax oblique rotation for rotation. We started with analysis of all the questions, selected questions whose absolute value of factor loading was 0.4 or more, eliminated questions that simultaneously reflect multiple factors and those with less commonality ( 0.16 and less), and then analyzed the data with an emphasis on creating a scale to show latent structure by repeating factor analysis. Table 11 shows the final results. We defined the number of factors as 5, based on the scree plot. The analysis results include $47 \%$ of all the information. The sampling adequacy ${ }^{29,30)}$ of the Kaiser-Meyer-Olkin measurement, which helps to determine the adequacy of factor analysis, is 0.8 , and we can say that it is sufficiently adequate to use factor analysis for the questions selected here. In this table, eighteen questions were excluded. These questions include those that asked about knowledge on radiation and risks.

The first factor value was large in questions from Q5-8, "I am concerned about radiation and radioactivity around us," to Q5-7, "I think there the effects of internal exposure are greater than the effects of external exposure in Fukushima Prefecture," in the list. This indicates a tendency for people to be concerned about radiation and about the effects of low-dose exposure. We call it the "Anxiety Factor." The questions include Q8-12, "I think the effects of low-dose exposure are transmitted to others like a virus," with a large Anxiety Factor value of 0.6. The second factor value was large in questions in the following order: Q7-3, Q7-2, Q7-4, Q7-1, and Q7-5. It mainly indicates that the level of knowledge on the notion of risk. We call it the "Risk Knowledge Factor." The third factor value was large in Q8-5, Q8-6, Q8-4, and Q8-3, which indicates people's distrust in the government's and experts' views regarding the effects of lowdose exposure. We call it the "Distrust Factor" and reflects distrust of sources of information on the effects of low-dose exposure. The fourth factor value was large in questions concerning food safety and indicates people's trust in food safety. We call it the "Food Safety Factor." These questions include Q8-11, "I am not concerned about any effects of low-dose exposure on myself." The fifth factor indicates people's desire to have risk determination criteria defined by the government (local government) and experts. We call it the "Demand Factor."

As we adopted the Promax method for the oblique rotation, there are correlations between the factors. Table 12 shows the correlations. Factor 1, "Anxiety Factor," has positive correlations with Factor 3, "Distrust Factor," and Factor 5, "Demand Factor," and shows negative correlations with Factor 2, "Risk Knowledge Factor," and Factor 4, "Food Safety Factor." The Risk Knowledge Factor has less of a relationship with the factors other than the Anxiety Factor. The Anxiety Factor has a negative correlation with the Food Safety Factor and a positive correlation with the Demand Factor.

Next, we provide relative features of each respondent and perform cluster analysis using factor scores, calculated for each factor, in order to get a rough estimate of the respondents' classification. For factor scores, we use the results calculated to create a scale to show latent structure. For cluster analysis, the Ward method ${ }^{31}$ (Euclidean distance) is adopted as 
Table 11 Factor analysis results

\begin{tabular}{|c|c|c|c|c|c|c|c|}
\hline & & Factor 1 & Factor 2 & Factor 3 & Factor 4 & Factor 5 & Commonality \\
\hline Q5-8 & I am concerned about radiation and radioactivity around us. & 0.80 & 0.07 & -0.09 & 0.03 & -0.04 & 0.55 \\
\hline Q5-10 & $\begin{array}{l}\text { I am concerned about radioactive elements in milk and dairy } \\
\text { products. }\end{array}$ & 0.74 & 0.09 & -0.06 & -0.01 & -0.03 & 0.50 \\
\hline Q8-1 & $\begin{array}{l}\text { I think low-dose exposure is scary regardless of exposure } \\
\text { dose. }\end{array}$ & 0.65 & -0.12 & 0.09 & 0.02 & -0.03 & 0.50 \\
\hline Q8-8 & $\begin{array}{l}\text { I think the effects of low-dose exposure have an influence on } \\
\text { overall health. (shortened) }\end{array}$ & 0.61 & -0.01 & 0.11 & -0.03 & 0.11 & 0.49 \\
\hline Q5-13 & $\begin{array}{l}\text { I am concerned about radioactive elements in food } \\
\text { (agricultural, animal and fishery products). }\end{array}$ & 0.60 & -0.04 & -0.10 & -0.16 & 0.14 & 0.48 \\
\hline Q8-13 & $\begin{array}{l}\text { I think the effects of low-dose exposure are passed on to } \\
\text { offspring. }\end{array}$ & 0.63 & 0.09 & 0.04 & -0.02 & 0.04 & 0.42 \\
\hline Q8-12 & $\begin{array}{l}\text { I think effects of low-dose exposure are transmitted to others } \\
\text { like a virus. }\end{array}$ & 0.60 & 0.06 & 0.01 & 0.14 & -0.30 & 0.32 \\
\hline Q5-3 & I think radiation and radioactivity are horrible. & 0.50 & -0.13 & -0.03 & -0.06 & 0.06 & 0.33 \\
\hline Q8-7 & $\begin{array}{l}\text { I think one of the effects of low-dose exposure is the } \\
\text { development of cancer in the future. }\end{array}$ & 0.51 & -0.07 & 0.05 & -0.06 & 0.19 & 0.42 \\
\hline Q5-7 & $\begin{array}{l}\text { I think the effects of internal exposure are greater than the } \\
\text { effects of external exposure in Fukushima Prefecture. }\end{array}$ & 0.48 & 0.04 & 0.14 & 0.19 & -0.03 & 0.23 \\
\hline Q7-3 & I know how to determine RISKS. & 0.05 & 0.78 & -0.07 & 0.02 & -0.15 & 0.60 \\
\hline Q7-2 & I have been educated about RISKS. & 0.06 & 0.71 & -0.04 & -0.02 & -0.14 & 0.49 \\
\hline Q7-4 & I know the meaning of RISKS. & 0.00 & 0.72 & -0.01 & -0.04 & 0.17 & 0.56 \\
\hline Q7-1 & I have thought about RISKS before. & -0.04 & 0.56 & 0.11 & -0.03 & 0.05 & 0.35 \\
\hline Q7-5 & I determine what RISKS are by myself. & -0.02 & 0.59 & 0.00 & -0.02 & 0.15 & 0.38 \\
\hline Q8-5 & $\begin{array}{l}\text { We cannot trust what experts say about the effects of low- } \\
\text { dose exposure. }\end{array}$ & -0.03 & -0.04 & 0.89 & -0.04 & -0.14 & 0.77 \\
\hline Q8-6 & $\begin{array}{l}\text { We cannot trust what medical doctors say about the effects of } \\
\text { low-dose exposure. }\end{array}$ & 0.00 & -0.09 & 0.69 & -0.03 & -0.09 & 0.48 \\
\hline Q8-4 & $\begin{array}{l}\text { We cannot trust what the government says about the effects } \\
\text { of low-dose exposure. }\end{array}$ & 0.07 & 0.02 & 0.66 & -0.20 & 0.08 & 0.64 \\
\hline Q8-3 & $\begin{array}{l}\text { I think different experts say different things about the effects } \\
\text { of low-dose exposure. }\end{array}$ & -0.03 & 0.08 & 0.60 & 0.11 & 0.13 & 0.38 \\
\hline Q5-11 & $\begin{array}{l}\text { I think the current government regulations ensure food } \\
\text { safety, including food from Fukushima. }\end{array}$ & -0.01 & -0.01 & -0.05 & 0.75 & -0.03 & 0.60 \\
\hline Q6-2 & We can trust the Food Safety Commission on food safety. & 0.11 & -0.04 & -0.19 & 0.64 & 0.07 & 0.45 \\
\hline Q5-15 & $\begin{array}{l}\text { I think the current regulation values for radioactive materials } \\
\text { in foods are adequate. }\end{array}$ & -0.10 & -0.02 & 0.00 & 0.64 & 0.09 & 0.47 \\
\hline Q8-11 & $\begin{array}{l}\text { I am not concerned about any effects of low-dose exposure } \\
\text { on myself. }\end{array}$ & -0.09 & 0.06 & -0.02 & 0.44 & -0.03 & 0.26 \\
\hline Q6-1 & $\begin{array}{l}\text { I think chemical toxicity is more dangerous than radioactive } \\
\text { materials in food. }\end{array}$ & -0.10 & -0.02 & 0.20 & 0.41 & 0.09 & 0.19 \\
\hline Q6-9 & $\begin{array}{l}\text { I think the government and prefectures (local government) } \\
\text { should clearly define criteria to determine RISKS. }\end{array}$ & 0.00 & -0.01 & -0.04 & 0.05 & 0.83 & 0.68 \\
\hline Q6-10 & $\begin{array}{l}\text { I think experts should clearly define criteria to determine } \\
\text { RISKS. }\end{array}$ & 0.09 & -0.01 & -0.12 & 0.02 & 0.82 & 0.68 \\
\hline \multicolumn{2}{|c|}{ Factor contribution } & 3.90 & 2.38 & 2.24 & 1.90 & 1.71 & \\
\hline \multicolumn{2}{|c|}{ Contribution rate } & 0.15 & 0.09 & 0.09 & 0.07 & 0.07 & \\
\hline \multicolumn{2}{|c|}{ Cumulative contribution } & 0.15 & 0.24 & 0.33 & 0.40 & 0.47 & \\
\hline
\end{tabular}

Table 12 Correlations between factors

\begin{tabular}{lrrrrr}
\hline & Factor 1 & Factor 2 & Factor 3 & Factor 4 & Factor 5 \\
\hline & \multicolumn{1}{c}{ Anxiety } & Risk knowledge & Distrust & Food safety & Demand \\
\hline Factor 1 & 1 & -0.21 & 0.38 & -0.44 & 0.21 \\
Factor 2 & -0.21 & 1 & 0.07 & 0.07 & -0.31 \\
Factor 3 & 0.38 & 0.07 & -0.31 & 1 & -0.20 \\
Factor 4 & -0.44 & 0.07 & 0.20 & -0.05 & 1 \\
Factor 5 & 0.21 & 0.05 & & & -0.05 \\
\hline
\end{tabular}




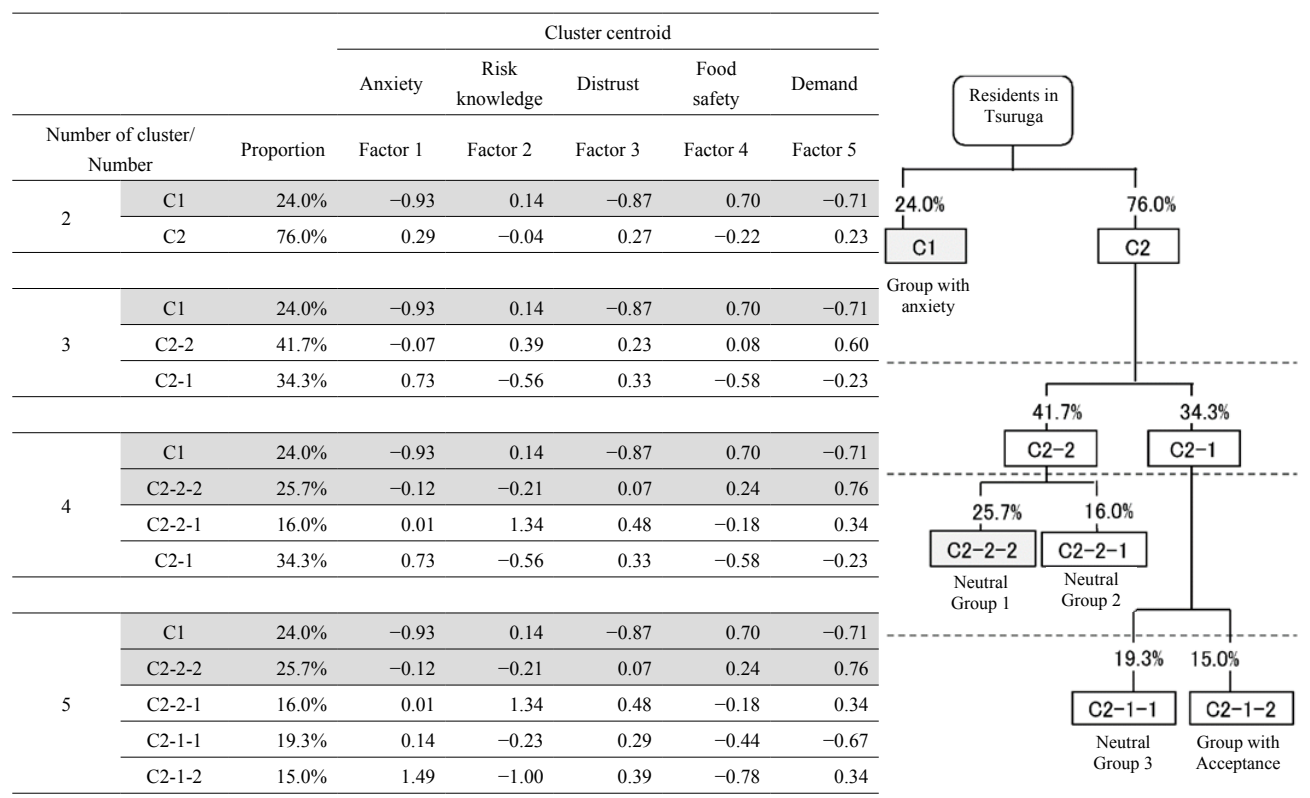

Figure 2 Results of cluster analysis based on factor scores

hierarchical clustering.

Figure 2 shows a dendrogram (tree diagram), which represents the process by which the data is summarized, and the cluster centroid of each factor per cluster classification. The cluster centroid represents the volume that indicates the features of each factor of the cluster. The positive and negative directions of values match the direction of the score allocated based on the 5-point scale (negative value indicates positive direction and positive value indicates negative direction). However, the factor score for each factor is standardized (average value: $0 /$ standard deviation: 1) in the factor and these scores represent the volumes that indicate relative features between the classified clusters.

First, we classified the respondents into two groups; Group C1 with $24 \%$ respondents and Group C2 with 76\% respondents. The cluster centroid of Factor 1, Anxiety Factor, for Group $\mathrm{C} 1$ is -0.93 , which means the respondents in this group have a high level of anxiety. Therefore, we labeled this group the "Anxiety Group." In contrast, the cluster centroid of Factor 1, Anxiety Factor, for Group C2 is 0.29 , which means that those in the group have a low level of anxiety. From the values of Factor 2, we can see that the difference in the level of knowledge on the notion of risk between the groups is small. The value of Factor 3 for Group C1 was -0.87 , which indicates that the respondents in the group distrust the views expressed about the effects of low-dose exposure. On the other hand, the value for Group C2 was 0.27 , which represents a less pronounced feeling of distrust. From the values of Factor 4, we can see that those in Group $\mathrm{C} 1$ do not have trust in food safety but those in Group C2 group do. From the values of Factor 5 , we can see that the demand for risk determination criteria to be defined is stronger among the respondents in Group C1 than it is among those in Group C2.

Next, we classified the respondents into three group; Group C2 is divided into C2-1 with $34.3 \%$ of respondents and $\mathrm{C} 2-2$ with $41.7 \%$ of respondents. From an analytical viewpoint, Group C2-1 and Group C2-2 are integrated into the C2 group. Group C1 (Anxiety) remains unchanged. Respondents in Group C2-1 tend to have less anxiety (0.73), are knowledgeable about the notion of risk $(-0.56)$, have less distrust of views on the impacts of low-dose exposure 
(0.33), have strong confidence in food safety $(-0.58)$ and demand that risk determination criteria be defined (-0.23). The features of Group C2-2 stand in contrast to those of Group C2-1 except for Factor 3, Distrust Factor and is close to those of Group C1 (Anxiety).

When we classify the respondents into four groups, Group C2-2 is divided into C2-2-1 with $16 \%$ of respondents and C2-2-2 with $25.7 \%$ of respondents. When classifying them into five groups, Group C2-1 is divided into C2-1-1 with 19.3\% and C2-1-2 with 15.0\%. Group $\mathrm{C} 1$ (Anxiety) remains unchanged. After the respondents were divided into two classifications, we can see that there is a big gap between the other groups. In cluster analysis, information to optimize the number of clusters is not given. In this study we divide respondents into five classifications, summarize the features of each group based on the classification that supports the dendrogram, and label them. In this analysis, the group showing a neutral trend was further classified into threes and we were able to provide comparative features of the five groups.

We labeled C2-2-2, C2-2-1, and C2-1-1 groups as "Neutral Group 1," "Neutral Group 2," and "Neutral Group 3," respectively. The anxiety levels of these three groups are almost the same and were at an intermediate level between Group C1 (Anxiety Group) and Group C2-1-2. As many of their other factors also show neutral features, we considered these three groups as neutral groups.

The features of Group C2-1-2 are in stark contrast to Group C1 (Anxiety Group). The respondents in C2-1-2 are different from those in other groups in having less anxiety (1.49), having knowledge on the notion of risk $(-1.00)$ and showing confidence in relation to food safety $(-0.78)$. These scores indicate those in the group accept the status quo and we labeled the group the "Acceptance Group." The features of the five classifications are clearly shown in Table 13, which indicates the order of groups on a factor basis. For example, compared to other groups, Group C1 (Anxiety Group) is ranked first in Factor 1, "Anxiety Factor," which indicates that respondents in the group have the strongest anxiety. The group is ranked fourth in Factor 2. As for the level of knowledge on the notion of risk, Group C2-2-1 (Neutral 2) is ranked fifth, the lowest.

Next, Table 14 shows features based on the differences between males and females and whether respondents have or do not have relatives who are engaged in nuclear/radiation-related fields. Slightly more females are in Group C1 (Anxiety Group) and more males are in Group C2-1-2 (Acceptance Group).

Also, more females are in C2-2-1 (Neutral 2). As for the difference based on whether respondents have or don't have relatives who are engaged in nuclear/radiation-related fields, slightly more respondents who answered "No" are in Group C1 (Anxiety Group) and more respondents who answered "Yes" are in Group C2-1-2 (Acceptance Group).

Table 13 Features of five classified groups (ranking)

\begin{tabular}{ccccccc}
\hline & Proportion & Anxiety & Risk knowledge & Distrust & Food safety & Demand \\
\cline { 2 - 7 } & Factor 1 & Factor 2 & Factor 3 & Factor 4 & Factor 5 \\
\hline $\begin{array}{c}\text { C1 } \\
\text { Anxiety Group } \\
\text { C2-2-2 } \\
\text { Neutral Group 1 } \\
\begin{array}{c}\text { C2-2-1 } \\
\text { Neutral Group 2 } \\
\text { C2-1-1 }\end{array}\end{array}$ & $24.0 \%$ & 1 & 4 & 1 & $\mathbf{5}$ & 1 \\
\hline $\begin{array}{c}\text { Neutral Group 3 } \\
\text { C2-1-2 }\end{array}$ & $16.0 \%$ & 3 & 3 & 2 & 4 & $\mathbf{5}$ \\
Acceptance Group & $15.3 \%$ & 4 & $\mathbf{5}$ & $\mathbf{5}$ & 3 & 3 \\
\hline
\end{tabular}


Table 14 Evaluation of five classified groups based on respondents' attributions. Symbols in this table comply with those in Table 7

\begin{tabular}{|c|c|c|c|c|c|}
\hline \multicolumn{6}{|c|}{ Difference among males and females } \\
\hline ** & Anxiety Group & Neutral Group 1 & Neutral Group 2 & Neutral Group 3 & Acceptance Group \\
\hline Males & - & & -- & & ++ \\
\hline Females & + & & ++ & & -- \\
\hline \multicolumn{6}{|c|}{ Whether respondents have relatives who are engaged in nuclear/ radiation-related fields } \\
\hline$*$ & Anxiety Group & Neutral Group 1 & Neutral Group 2 & Neutral Group 3 & Acceptance Group \\
\hline No & + & & & & -- \\
\hline Yes & - & & & & ++ \\
\hline
\end{tabular}

(b) Application of Principal Component Analysis (PCA)

In the factor analysis, some questions were excluded from an analysis accuracy point of view and therefore it became hard to see what impact the level of knowledge on the notion of risk had. Therefore, we adopted PCA, which allows us to perform analysis using all questions. In PCA, several common components are extracted from multidimensional observed variables and are referred to as principal components. Impact levels of observed variables on the principal components are calculated. The sum of the impact level times observed variables is the principal component. The percentage of principal components that have response results information is called the contribution rate.

The contribution rates are large in the order of the first, second and third principal factors. As each principal component is uncorrelated, the evaluation is easy.

Although PCA is often used for pre-evaluation of factor analysis, the purposes of these two analyses are different. While factor analysis aims to identify potential factors that have an impact on observed variables, PCA aims to create simple (composite) variables from observed variables and allows us to develop new scales where information is aggregated, and discover the structures of observed variable groups (conscious structures).

The first principal component with a $19.5 \%$ contribution rate is an indicator that shows anxiety and safety. Fear of radiation, perception that radiation is evil, fear, concerns and distrust of viewpoints on the effects of low-dose exposure, and people's attitude of avoiding purchasing food from or around Fukushima have similar degrees of impact of and are in the same direction as anxiety. On the other hand, the attitudes that low-dose exposure is not a concern and the government (local government) and experts can be trusted have similar degrees of impact of and are in the opposite direction to anxiety. Although knowledge of radiation, which was eliminated in factor analysis, is oriented in the direction opposite to anxiety, the degree of impact is low. Similarly, as we see from the five questions in Q7 that, although the level of knowledge on risks is oriented opposite to the direction of anxiety, the degree of impact is also low. Of these questions, Q7-3 "I know how to determine RISKS" has a high impact on the sense of safety.

The second principal component with a $8.2 \%$ contribution rate has a high impact on risk awareness and has a similar degree of impact of and is in the same direction as knowledge of radiation. Anxiety about radiation has an impact in the opposite direction to the level of knowledge on the notion of risk, but the value is smaller. Concerns regarding the impacts of low-dose exposure are oriented in the same direction as the level of knowledge on the notion of risk. The third principal component with a $7.2 \%$ contribution rate connects trust and distrust and the level of knowledge on the notion of risk and distrust. The contribution rates of the fourth and the following principal components are small.

When we evaluate the structure of people's awareness based on these, "Safety-Anxiety" and "Trust-Distrust," and "Knowledge on the notion of risk" and "Knowledge on radiation" 
are strongly related in the same directions, respectively. However, the relationships between "Safety-Anxiety" - "Trust-Distrust" and "Knowledge on the notion of risk" - "Knowledge on radiation" are low. Figure 3 shows the awareness index based on the PCA results.

\section{Summary and Discussion of the Survey}

This survey was a small awareness survey with 300 respondents. Although special care is required when discussing such values as response rates, we believe the analysis and evaluation of patterns were conducted well based on the impact on health of radiation and the differences between the levels of knowledge on the notion of risk as defined in this study.

In questions that ask respondents about their knowledge of radiation and risks, Q5-6, "Radiation and radioactivity are around us," were most strongly agreed to by respondents, followed by Q6-4, Q5-4, Q5-5, Q6-5 and Q5-6. On the other hand, Q8-12 "Effects of low-dose exposure are transmitted to others like a virus" was the concept most strongly rejected by respondents. There were no significant gaps in the nuclear power-related knowledge between males and females or those with and without relatives engaged in nuclear power-related fields. This means that residents of Tsuruga, overall, have a certain level of general knowledge of radiation and its associated risks.

Regarding attitudes to radiation, Q5-3, "Radiation is horrible," which is designed to ascertain people's awareness and beliefs, was most strongly agreed to by respondents, followed by Q8-9 and Q8-10, which ask about the effects of low-dose exposure. In the awareness survey ${ }^{11}$ conducted by Kimura and others in January 2014, there was a statement question that "Radiation and radioactivity are horrible," the responses to which informed us about the awareness of residents in the Tokyo metropolitan area and members of the Atomic Energy Society of Japan around the same time. Table 15 shows the results of the comparison made in this study. The

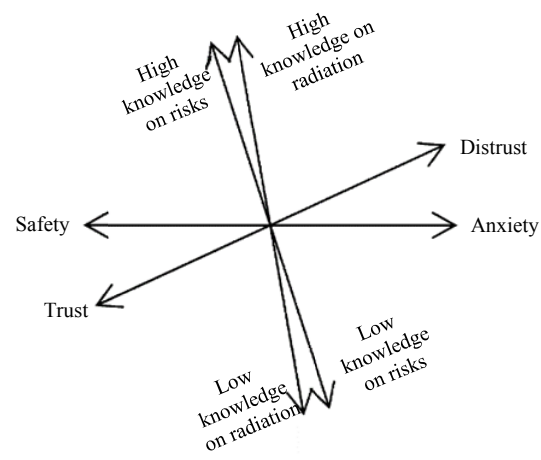

Figure 3 Awareness index based on PCA results

Table 15 Comparisons with other surveys

\begin{tabular}{lrrrrr}
\hline I think radioactivity and radiation are horrible. & \multicolumn{1}{l}{} \\
\hline & Positive & $\begin{array}{c}\text { Weak } \\
\text { positive }\end{array}$ & Neutral & $\begin{array}{c}\text { Weak } \\
\text { negative }\end{array}$ & Negative \\
\hline Residents in the Tokyo metropolitan area ${ }^{\text {a) }}$ & $63.6 \%$ & $26.6 \%$ & $8.6 \%$ & $0.8 \%$ & $0.4 \%$ \\
\hline Members of Atomic Energy Society of Japan $^{\text {a) }}$ & $8.8 \%$ & $26.2 \%$ & $25.1 \%$ & $18.3 \%$ & $21.0 \%$ \\
\hline Residents in Tsuruga city & $36.7 \%$ & $28.0 \%$ & $21.3 \%$ & $5.0 \%$ & $8.0 \%$ \\
\hline
\end{tabular}

a) Special Committee of Atomic Energy Society of Japan "Survey on energy and nuclear" Survey in FY $2013{ }^{11}$ 
differences in awareness between residents of Tsuruga and those in the Tokyo metropolitan area are assumed to be due to the distance from Fukushima and whether the area is a Power Plant Located Area. There were no marked differences in awareness between males and females, but differences were observed between those with and without relatives who are engaged in nuclear power-related fields.

As for the effects of low-dose exposure, people are concerned about this issue with respect to infants, toddlers and children, but, in Q8-7 and Q8-8, where victims are not specified, respondents show slightly less concern. In the responses to Q8-11, which showed that respondents are not concerned about such impacts on themselves, opinions were split and $43.3 \%$ of respondents answered "Neither," which shows respondents find it hard to form an opinion. Also, fewer respondents affirmed the statement in Q8-1, "Low-dose exposure is dangerous," than Q5-3, "Radiation is horrible." Differences were observed in these responses between males and females, but they were not marked between those with and without relatives who work in nuclear power-related fields.

Responses reflecting people's anxiety about radiation are widely distributed and overall such anxiety is negated. It is clear that there was a high rate of negative responses to Q5-8, Q5-9 and Q5-10, which asks respondents if they are concerned about radiation affecting their tap water, and milk, respectively. There were observable differences in these responses between males and females, but these differences were not marked between those with and without relatives working in the nuclear power field. It seems people in general are relatively unconcerned about radiation and the effects of low-dose exposure.

One of the features about the responses from residents of Tsuruga City was that, although they have a certain level of knowledge on radiation and risks and try to manage concerns about low-dose exposure, they also show anxiety at the same time. Also, overall, they feel strongly that risk determination criteria should be defined by the government and experts, but the responses were split.

We classified respondents into five groups using factor analysis and cluster analysis; Group C1 (Anxiety Group) and Group C2-1-2 (Acceptance Group) at opposite ends and three neutral groups comprising Groups C2-2-2, C2-2-1 and C2-1-1. Figure 4 shows the analysis results where the centroids of the five layered clusters organized by factor basis. The bar graph values show the relative strength of the features that each factor indicates based on the values in Figure 2.

The level of knowledge on the notion of risk of Group C1 (Anxiety Group), which has the highest level anxiety among the groups, was at moderate level and is not at a low level when compared with other groups. The anxiety and distrust shown by Group C2-2-1 (Neutral 2), which members have the lowest level of knowledge on the notion of risk, were at the intermediate level, between the other two neutral groups. The knowledge of Group C2-2-2 (Neutral 1) regarding the notion of risk was at a moderate level and the level of anxiety was higher than that in the other two neutral groups. Considering this together with the results of PCA, we can say that the level of knowledge on the notion of risk and Safety-Anxiety are not simply correlated. It was confirmed that the deficit model ${ }^{32}$, i.e., lack of knowledge on radiation and risks leads to anxiety, does not apply to residents of Tsuruga City. We found that knowing how to determine risks and the feeling of safety and security tend to be connected.

The demand that risk determination criteria be defined by the government and experts is high in Group C1 (Anxiety) and C2-1-1 (Neutral 3), and is at the same level in both groups, and is lowest in Group C-2-2 (Neutral). That in Group C2-2-1 (Neutral 2) and C2-1-2 (Acceptance) is almost the same, at the moderate level. The level of knowledge on the notion of risk is highest in Group C2-1-2 (Acceptance) and lowest in Group C2-2-1 (Neutral 2). The level of knowledge is high in Group C2-1-1 (Neutral 3), followed by C-2-2 (Neutral 1) and C1 (Anxiety) at a 


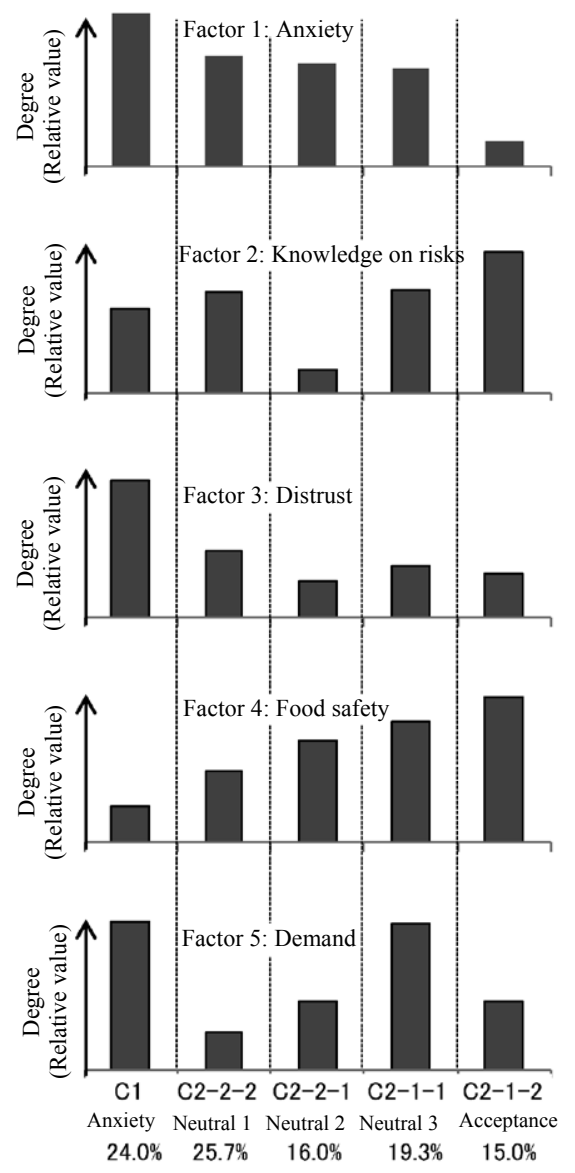

Figure 4 Features of the five classified groups

moderate level. The level of the demand to have risk determination criteria defined was about the same in Group C2-2-1 (Neutral 2), which has the highest level of knowledge on the notion of risk, as that in C2-1-2 (Acceptance), which has the lowest level of knowledge on the notion of risk. According to the correlation analysis provided in Table 9, demand for having risk determination criteria defined is independent of their level of knowledge on the notion of risk. It is explained by the features of each group.

Neutral Groups have intermediate features between Group C1 (Anxiety) and Group C2-1-2 (Acceptance) in most of the factors. For the Anxiety Factor and the Food Safety Factor, the values are high or low in the order of the groups listed in Figure 2, while, for other factors, values are irregularly distributed. Also, the table shows that knowledge on the notion of risk and distrust of experts that characterized Group C2-2-1 (Neutral 2) and the demand of Group C2-2-2 (Neutral 1) for having risk determination criteria defined exceed the features of Group C1 (Anxiety) and Group C2-1-2 (Acceptance), respectively. It is important to understand the features of the three neutral groups classified in Figure 2.

Group C2-2-2 (Neutral 1) (25.7\%) tends to choose "Neither" for questions in Tables 4 to 6 compared to other groups and this trend is observed in about half of the questions. This rate is high considering that the respondents in C2-2-1 (Neutral 2) responded "Neither" in about one third of the questions and Groups C2-1-1 (Neutral 3), C1 (Anxiety) and C2-1-2(Acceptance) in $1 / 4$ of questions. We can distinguish the features of neutral groups by looking at this 
trend of choosing "Neither." Only a few percent of all respondents responded negatively to the questions regarding their demand to have risk determination criteria defined by the government and experts, and most of them are in Group C2-1-2 (Acceptance). Responses to the questions regarding the demand to have risk determination criteria defined are concentrated in positive responses. The fact that Group C2-2-2 (Neutral 1) tended to choose "Neither" for their answers shows that their demand is weak overall. It means this group is highly likely to choose "Neither" and tends to choose "Neither" in the questions regarding demand for having risk determination criteria defined. This means they have the lowest demand for having risk determination criteria defined. We can say that Group C2-2-2 is the most typical neutral group that chooses neutral answers.

The respondents in Group C2-2-1 (Neutral 2) (16\%) think they lack knowledge regarding the notion of risk. They feel anxious about radiation to some degree, but they have the lowest level of distrust regarding information from government and experts about low-dose exposure. We thus assumed that their tendency to avoid determining whether to trust information from the government or experts led to an unwillingness to express distrust. They are considered to be a passive neutral group with little interest.

Although the characteristics of Group C2-1-2 (Neutral 3) (19.3\%) are close to those of C2-1-2 (Acceptance) as seen in Figure 2, they are very different in terms of the degree of anxiety and demand for having risk determination criteria defined. From the features of Group C2-1-2 (Acceptance), it is assumed that strong anxiety leads to strong demand. We can assume that the differences between the two groups are mostly dependent on whether they can accept the current status or not.

Both Group C1 (Anxiety) (24\%) and Group C2-1-1 (Neutral 3) (19.3\%) have high anxiety and strongly demand that risk determination criteria be defined. It shows neither group is satisfied with the current status.

It must be noted that the characteristics and rates of the groups described in the survey refer to only residents of Tsuruga City and not to people in general. Since the characteristics of residents could differ significantly depending on the area surveyed, it is desirable to compare them with similar awareness surveys conducted in other areas. We would like to analyze and evaluate the results of this study further and utilize them for research activities being undertaken in Tsuruga City in Fukui Prefecture by the authors.

\section{Conclusions}

This study performed an awareness survey and provided and discussed the analysis results related to how aware the residents of Tsuruga City are of radiation and evaluated their level knowledge on the notion of risk. In the awareness survey, we explored respondents' knowledge of and opinions about radiation and the notion of risk and tried to classify respondents based on their relevant opinions. From the classification results based on factor analysis and cluster analysis, we classified the respondents into five groups; two groups at opposite ends, the Anxiety Group (24\%) and Group of Acceptance (15\%) and three neutral groups $(25.7 \%, 16 \%$ and $19.3 \%$ respectively) and discussed their features. We think that classifying the neutral group, which tends to show a neutral attitude, into three sub-groups, based on features, provided useful information. We would like to formulate a model of a community-based risk communication method with the residents of Tsuruga City, utilizing the information acquired in this study. 
We would like to express our gratitude to Tomio Kinoshita, a fellow of International Institute for Advanced Studies, the Professor Emeritus of Kyoto University, for his useful advice and cooperation throughout the course of this study. This study was undertaken with a Grant-in-Aid for Scientific Research (25420902) from JSPS.

\section{References}

1) Naoki Yamano, Statement "How to Judge Low Dose Radiation Exposure," the eleventh page of the Mainichi Newspapers, October 29, 2013.

2) Policy and Publication Relations Office of Cabinet Office, "Public Opinion Poll on Radioactivity." http://www8.cao.go.jp/survey/s37/S37-07-37-05.html 1963. (final confirmation in May 2014).

3) Japan Atomic Energy Relations Organization, Consciousness Survey on the Word "Radiation," 2002.

4) Yuko Matsui, "The Relationship between Radiation Risks and Anxiety - From Comparison between Chest Radiography and Nuclear Power Plant -," INSS J, 10, 63-70 (2003).

5) Takeshi Murai, "Current Situation of Radiation Education and Survey on Radiation Consciousness," INSS J, 20, 28-37 (2013).

6) Fukushima City, Report on Citizen Consciousness Survey on Radiation. http://www.city.fukushima. fukushima.jp/uploaded/attachment/14143.pdf 2012. (final confirmation in May 2014).

7) Monetary Evaluation of Mitigation Measures of Nuclear Accident Research Group, Survey of Residents' Consciousness on Decontamination Implementation Plan. http://fukushima-survey.com 2013. (final confirmation in May 2014).

8) Tomoko Tsuchiya, Report on the Investigation of Citizens and Experts about Earthquakes, Tsunamis and Radiation. http://pari.u-tokyo.ac.jp/unit/ppcbpr_report2013.pdf 2013. (final confirmation in May 2014).

9) Keio University, "Special Survey on the Great East Japan Earthquake" (1st) - How did the psychology and behavior of the Japanese changed due to the earthquake?. http://www.keio.ac.jp/en/press_release/2011/kr7a430000094z75-att/120215_1.pdf 2012. (final confirmation in May 2014).

10) Japan Atomic Energy Relations Organization, Public Opinion Poll on Knowledge Dissemination and Enlightenment of Nuclear Energy Utilization. http://www.jaero.or.jp/data/01jigyou/tyousakenkyu.html 2012. (final confirmation in May 2014).

11) Special Committee of Atomic Energy Society of Japan, Questionnaire Survey on Energy and Nuclear Power (2013). http://ponpo.jp/forum/gakkai25.html 2014. (final confirmation in May 2014).

12) Consumer Affairs Agency, Consumer Consciousness Survey on Food Safety. http://www.caa.go.jp/jisin/ pdf/110715press.pdf 2011. (final confirmation in May 2014).

13) Consumer Affairs Agency, About the Results of Consumer Survey on Rumor Damage - Survey of Consciousness on Radioactive Substance etc. in Food -. http://www.caa.go.jp/safety/pdf/130311kouhyou_1. pdf 2013. (final confirmation in May 2014).

14) Environmental Marketing Theory Section, Graduate School of Global Environmental Studies, Kyoto University, Consumer Questionnaire on Radiation Exposure from Food. http://www.eeso.ges.kyoto-u. ac.jp/emm/ 2011. (final confirmation in May 2014).

15) Kazunari Minotani, "Empirical Study on Nuclear Information and Nuclear Power Consciousness" [I]: Focusing on the Statistical Survey in Tsuruga City, Fukui Prefecture, Institutional Repository of Rissho University, 1981, 29-77.

16) Kazunari Minotani, "Empirical Study on Nuclear Information and Nuclear Power Consciousness" [II]: Focusing on the Statistical Survey in Tsuruga City, Fukui Prefecture, Institutional Repository of Rissho University, 1983, 1-69.

17) Kazunari Minotani, "Empirical Study on Nuclear Information and Nuclear Power Consciousness" [I]: Focusing on the Statistical Survey in Kashiwazaki City, Niigata Prefecture, Institutional Repository of Rissho University, 1982, 61-91.

18) Kazunari Minotani, "Formation/Transformation of Nuclear Consciousness and Acceptance of Nuclear Information": Focusing on the Specimen Investigation in Hamaoka Town, Shizuoka Prefecture, Institutional Repository of Rissho University, 1985, 133-166.

19) Benibana Saru, Wataru Shōda, "A Study on Risk Cognition Attitudes of Residents near Nuclear Power Plants towards Nuclear Power," Ergonomics, 36 [4], 215-221 (2000).

20) Institute for Policy Sciences, Grasping Inhabitants Awareness of the Nuclear Location Area, Relationship with the Nuclear Location Area in the Era of Power Liberalization by Survey of Other Enterprises and Overseas Cases, etc. http://www.ifeng.or.jp/wordpress/wpcontent/uploads/2012/06/CR-2001-03. pdf 2002 (final confirmation in May 2014).

21) Takaaki Kato, Masahisa Hatta, Masashi Nishikawa, Shiro Matsumoto, "Economic and Financial Benefits 
as a Compensation for Living Near a Nuclear Power Station A Case Study of Kashiwazaki-Kariwa Nuclear Power Station,” Trans. At. Energy Soc. Jpn., 6 [4], 404-420 (2007).

22) Motoko Kosugi, Tomoko Tsuchiya, Residents' Consciousness on Nuclear Power and Energy Problems in Fukui Prefecture, Report of Central Research Institute of Electric Power Industry, 2007.

23) Motoko Kosugi, Mami Kamiya, Tomoko Tsuchiya, Residents' Consciousness on Nuclear Power and Energy Problems in Ibaraki Prefecture, Report of Central Research Institute of Electric Power Industry, 2008.

24) Megumi Ono, Yoshiumi Kawamoto, "Evaluation of Living Environment in Nuclear Location Areas," Bulletin of the Regional Environmental Research and Education Center, University of Fukui, 15, 115122 (2008).

25) Outline of the results of the Local Community and Nuclear Power Questionnaire Survey II by the Local Community and Nuclear Power research team, Regional Studies Institute, Ibaraki University, 2011.

26) Outline of the results of the Questionnaire Survey on Nuclear Accident and Everyday Life by the Local Community and Nuclear Power research team, Regional Studies Institute, Ibaraki University, 2011.

27) Masatake Kamizono, Takayasu Eguchi, Kohei Seki, "Consciousness Structure of Matsue Citizen towards the Operation of Shimane Nuclear Power Station,” San'in Research (No. 5), 2012.

28) Shigenobu Aoki, Statistics self-study note, http://aoki2.si.gunma-u.ac.jp/lecture/index.html 2011. (final confirmation in May 2014).

29) H. Kaiser, J. Rice, “Little jiffy, mark IV," Educ. Psychol. Meas., 34, 111-117 (1974).

30) H. Kaiser, "An index of factorial simplicity," Psychometrika, 39[1], 31-36 (1974).

31) J. Word, "Hierarchical grouping to optimize an objective function," J Am Stat Assoc, 58[301], 236-244 (1963).

32) J. Ziman, "Public understanding of science," Sci Technol Hum Val, 16, 99-105 (1991). 


\section{-Appendix: Survey of Tsuruga Inhabitants Concerning their Living Situation and Attitudes to Radiation (Only questions relevant to this study are excerpted. The layout of the questionnaire is provided as in the original.)-}

【Tell us your opinions concerning radiation and radioactivity.】

Q5. Do you agree or disagree with the statement in Questions 1) to 14) about radiation and radioactivity. Circle the number of the answer that best fits your opinion.

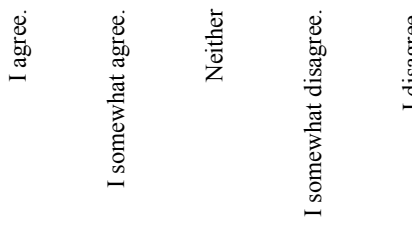

1) I think radiation and radioactivity are evil.

2) I cannot classify radiation and radioactivity as good or bad.

3) I think radiation and radioactivity are horrible.

4) I think radiation and radioactivity can sometimes be useful to human beings.

5) I think radiation and radioactivity can be horrible or not horrible, depending on the amount.

6) I think radiation and radioactivity are around us.

7) I think the effects of internal exposure are greater than the effects of external exposure in Fukushima Prefecture.

8) I am concerned about radiation and radioactivity around us.

9) I am concerned about radioactive elements in tap water.

10) I am concerned about radioactive elements in milk and dairy products.

11) I think the current government regulations ensure food safety, including food from Fukushima.

12) I want to avoid purchasing milk and dairy products from Ibaraki and Tochigi.

13) I am concerned about radioactive elements in food (agricultural, animal and fishery products).

14) I want to avoid purchasing food (agricultural, animal and fishery products) from Fukushima.

15) I think the current regulation values for radioactive materials in foods are adequate.

\begin{tabular}{|c|c|c|c|c|}
\hline & $\downarrow$ & $\downarrow$ & $\downarrow$ & $\downarrow$ \\
\hline & 2 & 3 & 4 & 5 \\
\hline 1 & 2 & 3 & 4 & 5 \\
\hline 1 & 2 & 3 & 4 & 5 \\
\hline & + & 1 & + & -1 \\
\hline 1 & 2 & 3 & 4 & 5 \\
\hline & + & + & + & -1 \\
\hline 1 & 2 & 3 & 4 & 5 \\
\hline 1 & 2 & 3 & 4 & 5 \\
\hline & + & + & 十 & -1 \\
\hline 1 & 2 & 3 & 4 & 5 \\
\hline 1 & 2 & 3 & 4 & 5 \\
\hline & + & + & + & -1 \\
\hline 1 & 2 & 3 & 4 & 5 \\
\hline 1 & 2 & 3 & 4 & 5 \\
\hline$\vdash$ & + & + & + & -1 \\
\hline 1 & 2 & 3 & 4 & 5 \\
\hline & 1 & + & 4 & -1 \\
\hline 1 & 2 & 3 & 4 & 5 \\
\hline 1 & 2 & 3 & 4 & 5 \\
\hline$\vdash$ & + & + & 4 & -1 \\
\hline 1 & 2 & 3 & 4 & 5 \\
\hline 1 & 2 & 3 & 4 & 5 \\
\hline$\vdash$ & 1 & + & & \\
\hline
\end{tabular}


【Tell us your opinions concerning RISKS and food safety.】

Q6. Do you agree or disagree with each statement of Questions 1) to 11) about RISKS and food safety. Circle the number of the answer that best fits your opinion.

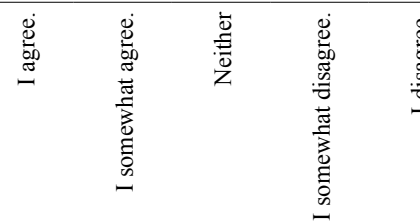

1) I think chemical toxicity is more dangerous than radioactive materials in food.

$\begin{array}{lllll}\downarrow & \downarrow & \downarrow & \downarrow & \downarrow \\ 1 & 2 & 3 & 4 & 5\end{array}$

2) We can trust the Food Safety Commission on food safety.

3) We can trust the Ministry of Health, Labour and Welfare and Ministry of Agriculture, Forestry and Fisheries of Japan on food safety.

4) I think there are various RISKS in our society.

$1+1$

$\begin{array}{lllll}1 & 2 & 3 & 4 & 5\end{array}$

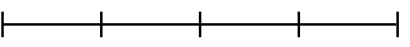

$\begin{array}{lllll}1 & 2 & 3 & 4 & 5\end{array}$

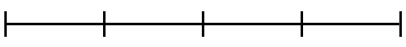

$\begin{array}{lllll}1 & 2 & 3 & 4 & 5\end{array}$

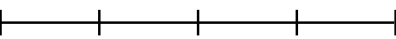

5) I think radiation and radioactivity are just one of many RISKS.

6) I think some RISKS can have a bad influence on us.

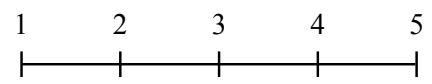

$\begin{array}{llll}2 & 3 & 4 & 5\end{array}$

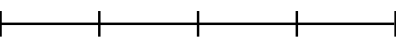

7) I think some RISKS can have a good influence on us.
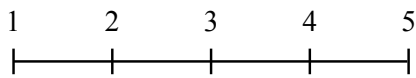

$\begin{array}{lllll}1 & 2 & 3 & 4 & 5\end{array}$

8) I think mineral water is safer than tap water.

9) I think the government and prefectures (local government) should clearly define criteria to determine RISKS.

10) I think experts should clearly define criteria to determine RISKS.

11) I think domestic food contains less radioactive materials than imported food.
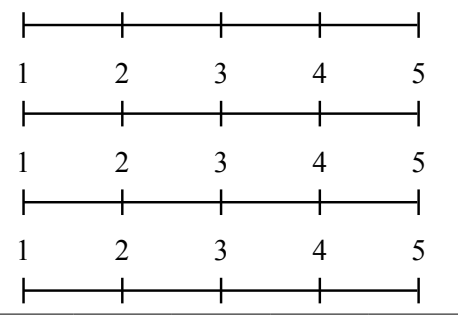

Q7. Do you agree or disagree with each statement of Questions 1) to 5) about RISKS. Circle the number of the answer that best fits your opinion.

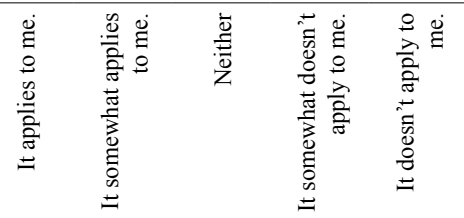

1) I have thought about RISKS before.

2) I have been educated about RISKS.

$\begin{array}{lcccc}\downarrow & \downarrow & \downarrow & \downarrow & \downarrow \\ 1 & 2 & 3 & 4 & 5 \\ 1 & \downarrow & \downarrow & + & -1\end{array}$
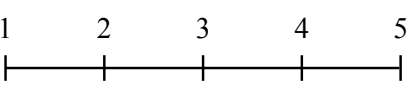

3) I know how to determine RISKS.

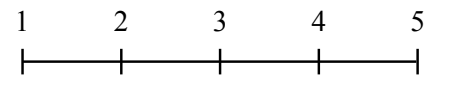

4) I know the meaning of RISKS.

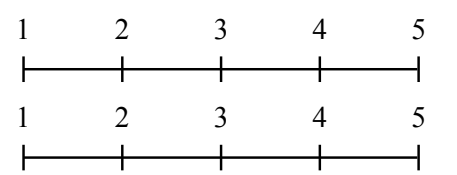

5) I determine what RISKS are by myself. 
【Tell us know your opinions concerning low-dose exposure.】

Q8. Do you agree or disagree with each statement of Questions 1) to 13) about low-dose exposure. Circle the number of the answer that best fits your opinion

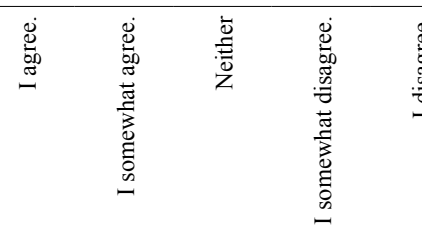

1) I think low-dose exposure is scary regardless of exposure level.

$\begin{array}{lllll}\downarrow & \downarrow & \downarrow & \downarrow & \downarrow \\ 1 & 2 & 3 & 4 & 5 \\ & \downarrow & & & 1\end{array}$

2) I think the effects of low-dose exposure are uncertain.

3) I think different experts say different things about the effects of low-dose exposure.

4) We cannot trust what the government says about the effects of low-dose exposure.

5) We cannot trust what experts say about the effects of low-dose exposure.

6) We cannot trust what doctors say about the effects of low-dose exposure.

7) I think one of the effects of low-dose exposure is the development of cancer in the future.

8) I think the effects of low-dose exposure not only leads to the development of cancer in the future, but also influences overall health.

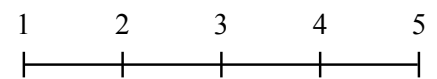

$\begin{array}{lllll}1 & 2 & 3 & 4 & 5\end{array}$

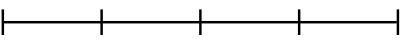

$\begin{array}{lllll}1 & 2 & 3 & 4 & 5\end{array}$

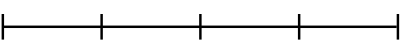

$\begin{array}{lllll}2 & 3 & 4 & 5\end{array}$

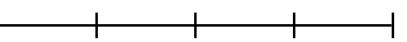

$1 \quad 2 \quad 3 \quad 4 \quad 5$

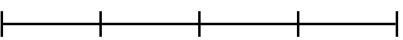

$\begin{array}{lllll}1 & 2 & 3 & 4 & 5\end{array}$
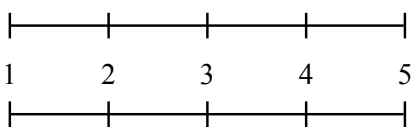

9) I think low-dose exposure negatively affects infants.

10) I think low-dose exposure negatively affects toddlers and children.

11) I am not concerned about any effects of low-dose exposure.

12) I think the effects of low-dose exposure are transmitted to others like a virus.

$\begin{array}{lllll}1 & 2 & 3 & 4 & 5\end{array}$
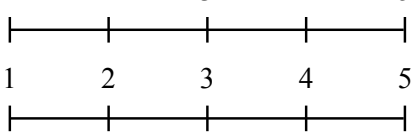

$\begin{array}{lllll}1 & 2 & 3 & 4 & 5\end{array}$
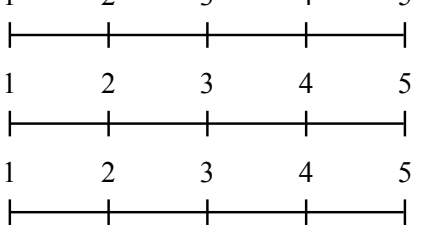

【Finally, tell us about yourself.】

F1. What is your gender? $\cdots \cdots \cdots \cdots 1$. Male 2. Female

Do you have any relatives who live with you and who are engaged in work related to nuclear power or radiation

industries? Circle the numbers of all answers that apply to you.
1. Self
3. Father/Mother
5. Grandson/Granddaughter
7. Relative
2. Spouse 4. Children
6. Brother/Sister
8. Others: 